\title{
Efficacy and practice of facemask use in general population: a systematic review and meta-analysis
}

Hui Li ${ }^{1,9}$, Kai Yuan (iD ${ }^{1,9}$, Yan-Kun Sun ${ }^{1,9}$, Yong-Bo Zheng ${ }^{1}$, Ying-Ying Xu ${ }^{2,3}$, Si-Zhen Su ${ }^{1}$, Yu-Xin Zhang ${ }^{1,3}$, Yi Zhong ${ }^{1,4}$, Yi-Jie Wang ${ }^{1,4}$, Shan-Shan Tian ${ }^{1}$, Yi-Miao Gong ${ }^{1,4}$, Teng-Teng Fan ${ }^{1}$, Xiao Lin ${ }^{1,4}$, Nina Gobat ${ }^{5}{ }^{5}$, Samuel Yeung Shan Wong ${ }^{6}$, Emily Ying Yang Chan ${ }^{7}$,

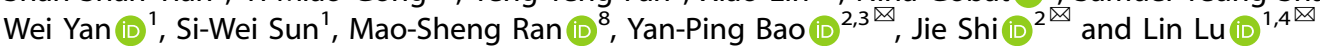

(c) The Author(s) 2022

In recent decades, respiratory infections, including SARS, HINI and the currently spreading COVID-19, caused by various viruses such as influenza and coronavirus have seriously threatened human health. It has generated inconsistent recommendations on the mandatory use of facemasks across countries on a population level due to insufficient evidence on the efficacy of facemask use among the general population. This meta-analysis aimed to explore (1) the efficacy of facemask use on preventing respiratory infections, and (2) the perceptions, intentions, and practice about facemask use among the general population worldwide. We searched PubMed, MEDLINE, Web of Science, Cochrane, bioRxiv, and medRxiv databases since inception to August 17, 2020. From 21,341 records identified, eight RCTs on facemask in preventing infections and 78 studies on perception, intention, and practice of facemask use among the general population were included in the analysis. The meta-analysis of RCTs found a significant protective effect of facemask intervention $\left(\mathrm{OR}=0.84 ; 95 \% \mathrm{Cl}=0.71-0.99 ; l^{2}=0 \%\right)$. This protective effect was even more pronounced when the intervention duration was more than two weeks $\left(\mathrm{OR}=0.76 ; 95 \% \mathrm{Cl}=0.66-0.88 ; I^{2}=0 \%\right)$. The meta-analysis of observational studies on perception, intention, and practice on facemask use showed that $71 \%$ of respondents perceived facemasks to be effective for infection prevention, $68 \%$ of respondents would wear facemasks, and $54 \%$ of respondents wore facemasks for preventing respiratory infections. Differences in perception, intention, and practice behavior of facemask use in different regions may be related to the impact of respiratory infections, regional culture, and policies. The governments and relevant organizations should make effort to reduce the barriers in the use of facemasks.

Translational Psychiatry (2022)12:49; https://doi.org/10.1038/s41398-022-01814-3

\section{INTRODUCTION}

In recent decades, respiratory infections, including SARS, HINI and the currently spreading COVID-19, caused by various viruses such as influenza and coronavirus have seriously threatened human health, of which the novel virus with the capacity to efficiently spread with sustained human-to-human transmission may trigger a pandemic [1]. Medical facemasks (or surgical masks) are routinely used as personal protective equipment to protect people from influenza and other respiratory infections in healthcare settings, by providing a physical barrier against potentially infectious droplets [2]. Although a recent metaanalysis suggested that wearing facemasks could significantly reduce the risk of virus infection [3], particularly for airborne diseases, there has been heated debate continuing during the initial stage of COVID-19 pandemic on the effectiveness of facemask use by the general public in the community settings to prevent the transmission. It has generated inconsistent recommendations on the mandatory use of facemasks across countries at a population level due to insufficient evidence on the efficacy of facemask use among the general population [4]. As with overtime changes, WHO, as well as other national disease control departments like US CDC, have finally recommended that masks should be used as part of a comprehensive strategy of measures to suppress transmission of COVID-19 [5].

The efficacy of facemask use on preventing respiratory infections is still controversial, especially in community with insufficient proofs. Several randomized controlled trials (RCTs) on the efficacy of facemasks have been conducted in community settings, including households [6-10], university residence halls $[11,12]$, and Hajj Pilgrims tents [13], while, given many of the studies were just conducted over a single season and low adherence of facemask use, they are still not able to provide

\footnotetext{
${ }^{1}$ Peking University Sixth Hospital, Peking University Institute of Mental Health, NHC Key Laboratory of Mental Health (Peking University), National Clinical Research Center for Mental Disorders (Peking University Sixth Hospital), Chinese Academy of Medical Sciences Research Unit (No.2018RU006), Peking University, 100191 Beijing, China. ${ }^{2}$ National Institute on Drug Dependence and Beijing Key Laboratory of Drug Dependence, Peking University, 100191 Beijing, China. ${ }^{3}$ School of Public Health, Peking University, 100191 Beijing, China. ${ }^{4}$ Peking-Tsinghua Centre for Life Sciences and PKU-IDG/McGovern Institute for Brain Research, Peking University, Beijing, China. ${ }^{5}$ Nuffield Dept of Primary Care

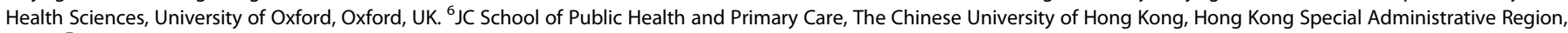

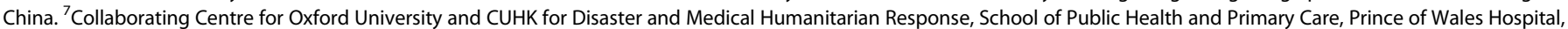

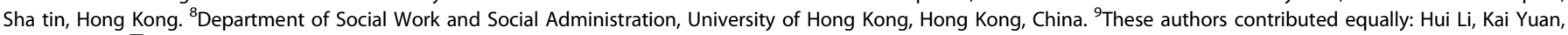
Yan-Kun Sun. ${ }^{凶}$ email: baoyp@bjmu.edu.cn; shijie@bjmu.edu.cn; linlu@bjmu.edu.cn
}

Received: 2 April 2021 Revised: 14 December 2021 Accepted: 18 January 2022

Published online: 01 February 2022 
conclusive results. Previous studies including two meta-analyses on the efficacy of facemask use for preventing transmission of pandemic influenza [14, 15] also provided inconsistent conclusions, while a recent meta-analysis including 14 randomized controlled trials did not support a substantial effect on transmission of laboratory-confirmed influenza. [14] A meta-analysis suggested that disposable surgical masks or reusable 12-16-layer cotton masks were associated with protection from viral transmission in non-healthcare setting. [3] However, it did not differentiate the evidence of surgical masks and general cotton masks, especially in the non-health care setting including multiple settings of community, household, and family contacts. [3] Recent two studies (a rapid review on COVID-19 and a meta-analysis) demonstrated that facemask use could reduce the risk of respiratory infections transmission $[16,17]$. However, these studies included some of the clinical trials using the hand sanitizer and facemask as intervention instead of only facemask, which might overestimate the efficacy of facemask use. Thus, more convincing evidence of the efficacy of wearing facemasks in general population is urgently needed.

Beside the efficacy, the perception, intention, and practice towards facemasks use in general population is vital for the adherence of facemask use during pandemics or epidemics. The attitude towards facemasks use among the population should be crucial for predicting the results of the related policies. Evidence shows that the selfreported perception, intention, and practice towards facemask use in the general population vary in different countries or regions [18, 19]. According to the health belief model, perceived susceptibility, severity, barriers, benefits, and cues to action have an influence on the practice of facemask-wearing $[20,21]$. However, there is no integrated evidence on the perception, intention, and practice towards facemasks use during pandemics including COVID-19 from a global view, which will support the governments and disease control departments to make evidence-based recommendations on facemask use in the control of respiratory infections and to reduce morbidity and mortality associated with the pandemic among general population worldwide.

Therefore, this systematic review and meta-analysis aimed to firstly evaluate the efficacy of medical masks use on reducing the respiratory infection in community settings, and secondly estimate the perception, intention, and practice regarding wearing facemasks among the general population during infectious disease pandemic.

\section{METHODS \\ Search strategy and selection criteria}

This systematic review and meta-analysis followed the Preferred reporting items for systematic reviews and meta-analyses (PRISMA) guidelines (Table S1). We included RCTs exploring the efficacy of wearing facemask on reducing respiratory infection in community settings, in which study subjects were assigned into intervention and control groups using random allocation. Second, we included observational studies to evaluate the perception, intention, and practice regarding wearing facemasks among general populations. We searched PubMed, MEDLINE, Web of Science, Cochrane, medRxiv, and bioRxiv databases since inception to August 17, 2020, with no language restrictions. The search terms were developed in collaboration with a research librarian (See Appendix). All articles were double screened (by Hui $\mathrm{Li}$ and 1 Ying-Ying $\mathrm{Xu}$ ) on title and abstract. All full-text articles identified were reviewed by Yong-Bo Zheng, Si-Zhen Su, and $\mathrm{Yu}$-Xin Zhang. Two independent reviewers (Hui $\mathrm{Li}$ and Si-Zhen Su) extracted data from included studies.

The studies on the efficacy of facemasks use were included if they met the following criteria: (1) concerning the relationship between medical masks and preventing respiratory infection in community settings (an open setting without confinement and special care for the participants); (2) applying RCT design; and (3) providing complete data of cases and controls for calculating an odds ratios (ORs), relative risks (RRs) with $95 \%$ confidence interval (Cl). The exclusive criteria were as follows: (1) the subjects were health care workers or studies conducted in hospital-specific settings; (2) the intervention was not using facemasks alone (e.g. combining the facemasks and hand hygiene); and (3) reviews, guidelines, theoretical models and non-research based communications such as letters to the editor.

The studies reporting perception, intention, and practice towards facemask use in general population were included. The inclusion criteria were: (1) concerning the perceived efficacy of facemask for preventing respiratory infection, the intention to wear facemasks or the practice of facemask use in the past; (2) the studies among the general population; and (3) providing complete data for prevalence calculation. Exclusive criteria were as follows: (1) the included subjects were health care workers; (2) no certain data given to obtain the prevalence; and (3) reviews, guidelines, theoretical models and non-research-based communications such as letters to the editor. We registered our systematic review on PROSPERO (number: CRD42020191447).

\section{Assessment of study quality}

Two authors (Yong-Bo Zheng and Yi Zhong) assessed the quality of all included studies. The quality of RCTs was assessed in accordance with Cochrane Handbook for Systematic Reviews of Interventions. The Joanna Briggs Institute (JBI) critical appraisal checklist was used for observational studies. Disagreements were resolved by a third author (Si-Zhen Su).

\section{Data extraction}

The data were independently extracted from eligible papers by researchers ( $L i \mathrm{H}$, Zheng YB, Zhong $\mathrm{Y}$ and Wang $\mathrm{YJ}$ ) and the extracted data were subsequently cross-checked. Discrepancies were discussed until a consensus was reached. The following information was extracted from each study of RCTs: (1) first author, (2) year of publication, (3) facemask using places, (4) research site (country), (5) total sample size, (6) intervention designs, (7) follow up times, (8) influenza-like illness (ILI) case definition, and (9) the results of the risk for ILI infection after the interventions (see Table 1). The following information was extracted from each of crosssectional studies: (1) first author, (2) year of publication, (3) total sample size, (4) type of epidemics of infectious diseases, (5) research site (country), (6) age of participants, (7) perceived efficacy, (8) intervention designs, and (9) practice about facemask use (see Table 2).

\section{Data analysis}

For the data from RCT studies concerning the relationship between facemask use and preventing respiratory infection in community settings, we used inverse variance weighted random effect models to pool the logtransformed odds ratios (ORs) and relative risk (RRs) from primary studies. If multiple models were presented within a study, we selected the multivariable model in each study for meta-analysis. Heterogeneity across studies was measured using the $I^{2}$ statistics with the chi-square $p$ value. Subgroup analysis was used to explore the relationship between facemask use and risk of respiratory infections in different duration, intervention designs and settings.

The pooled prevalence of the attitudes and behaviors towards facemasks was estimated by inverse variance weighting random-effects modeling. Subgroup analysis was conducted on the basis of different diseases, broad WHO regional classification, facemask use places and situations for study-specific effect estimates. Meta-regression was also used to assess the differences between these subgroups.

Sensitivity analyses were performed to assess the influence of each study, omitting the studies with the largest weight on the overall result one by one. Publication bias was investigated using funnel plots and formally tested using Begg's test and Egger's tests. All of the statistical analysis was performed using STATA 12 software, and values of $p<0.05$ were considered statistically significant.

\section{RESULTS}

We identified 21,341 articles in the initial database search, of which 126 were retrieved based on their titles and abstract content. After excluding 40 articles that did not meet our inclusion criteria (see Table S2 for exclusion reasons), eight were eligible for RCT studies on the efficacy of facemask use, and 78 were eligible for studies about perception, intention, and practice towards wearing facemasks based on our inclusion criteria (see Fig. 1). 


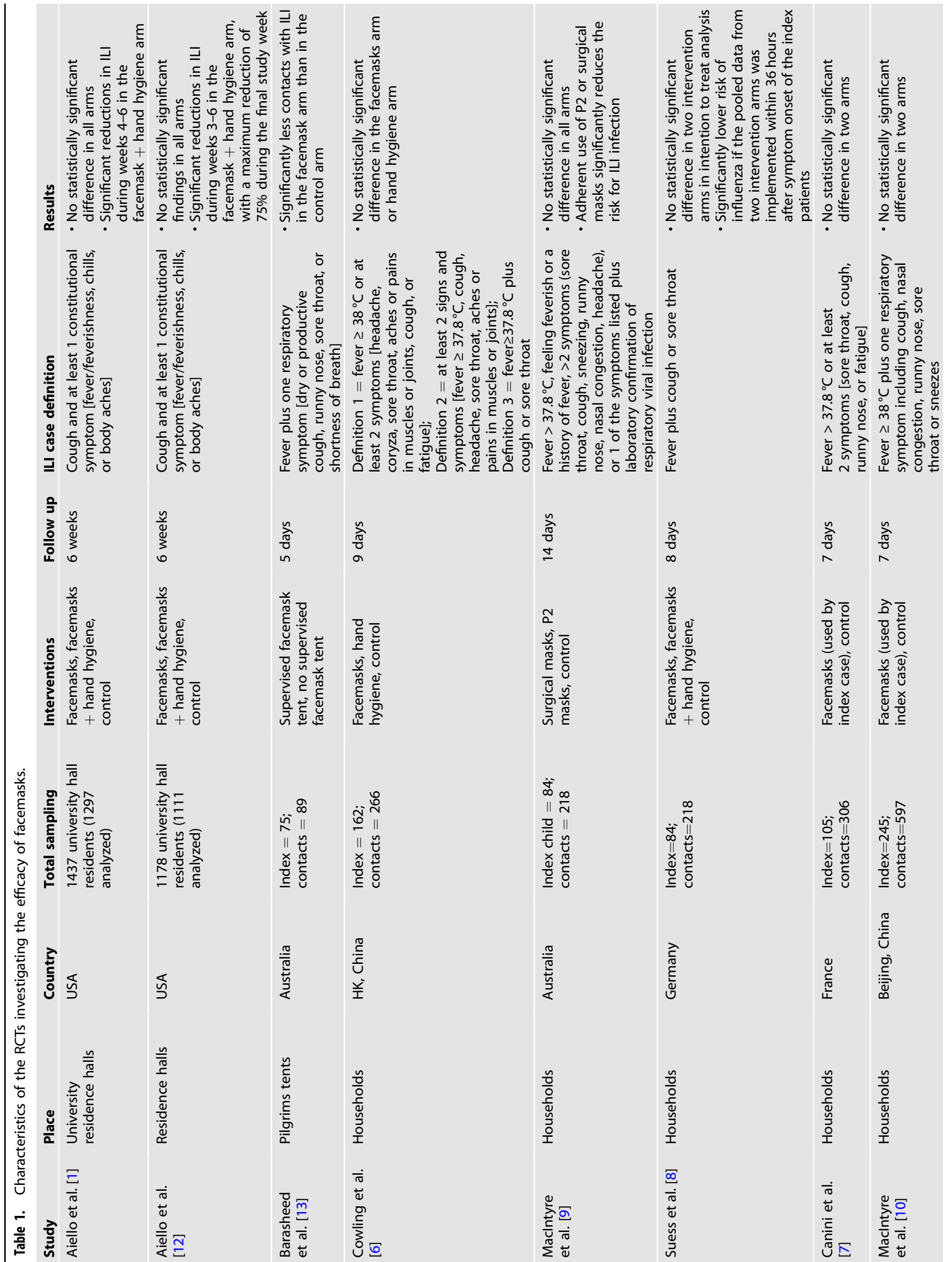




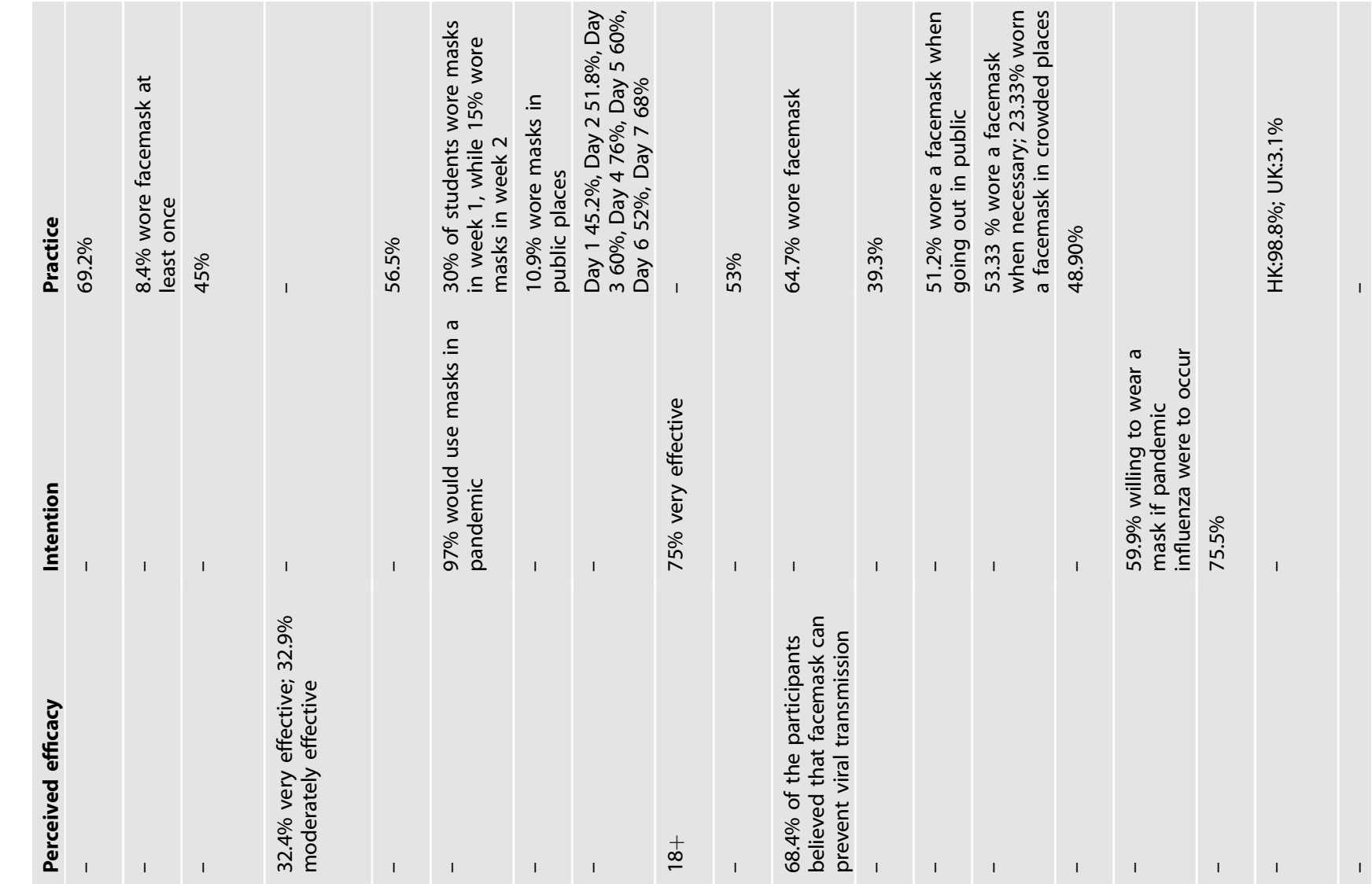

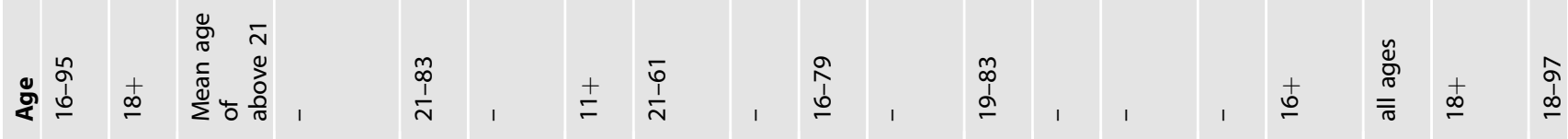

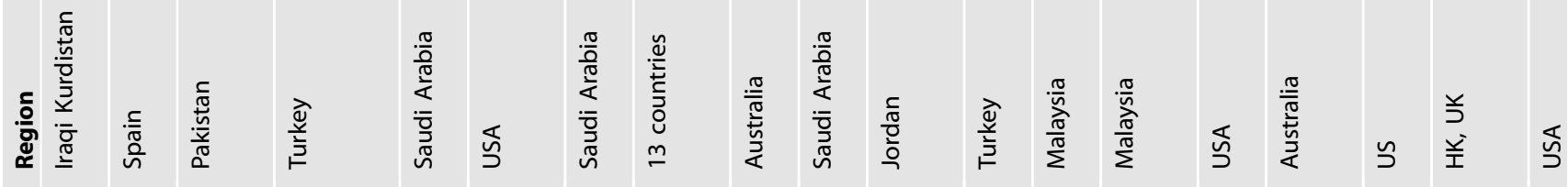

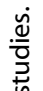

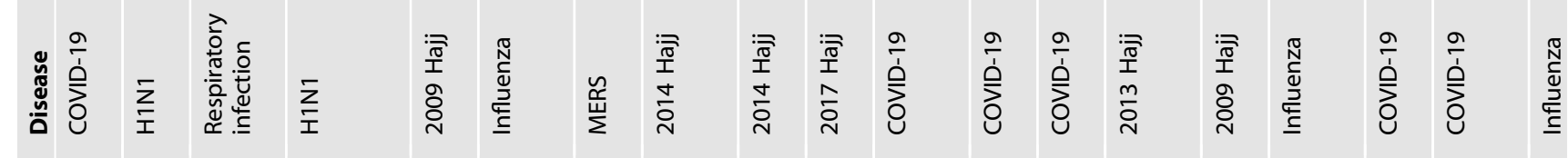
气ัญ

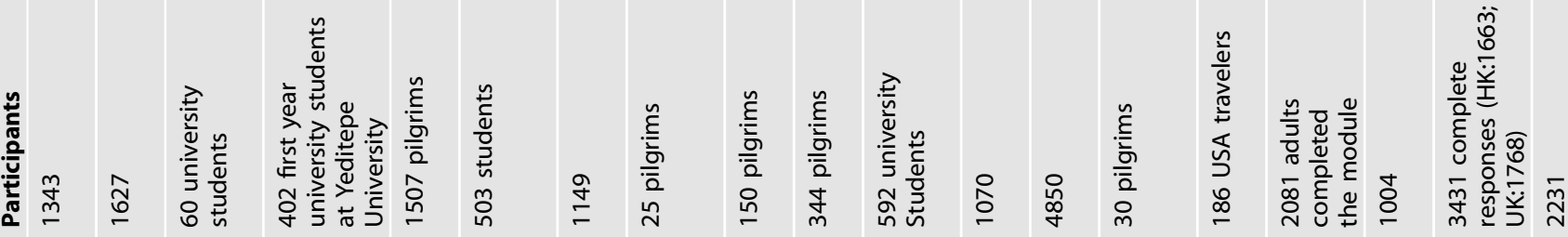

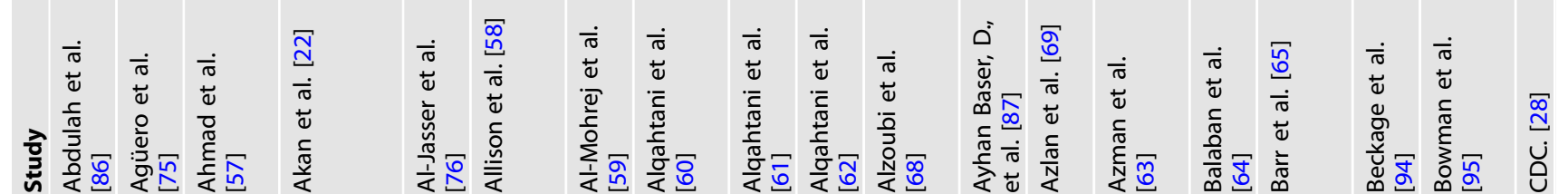



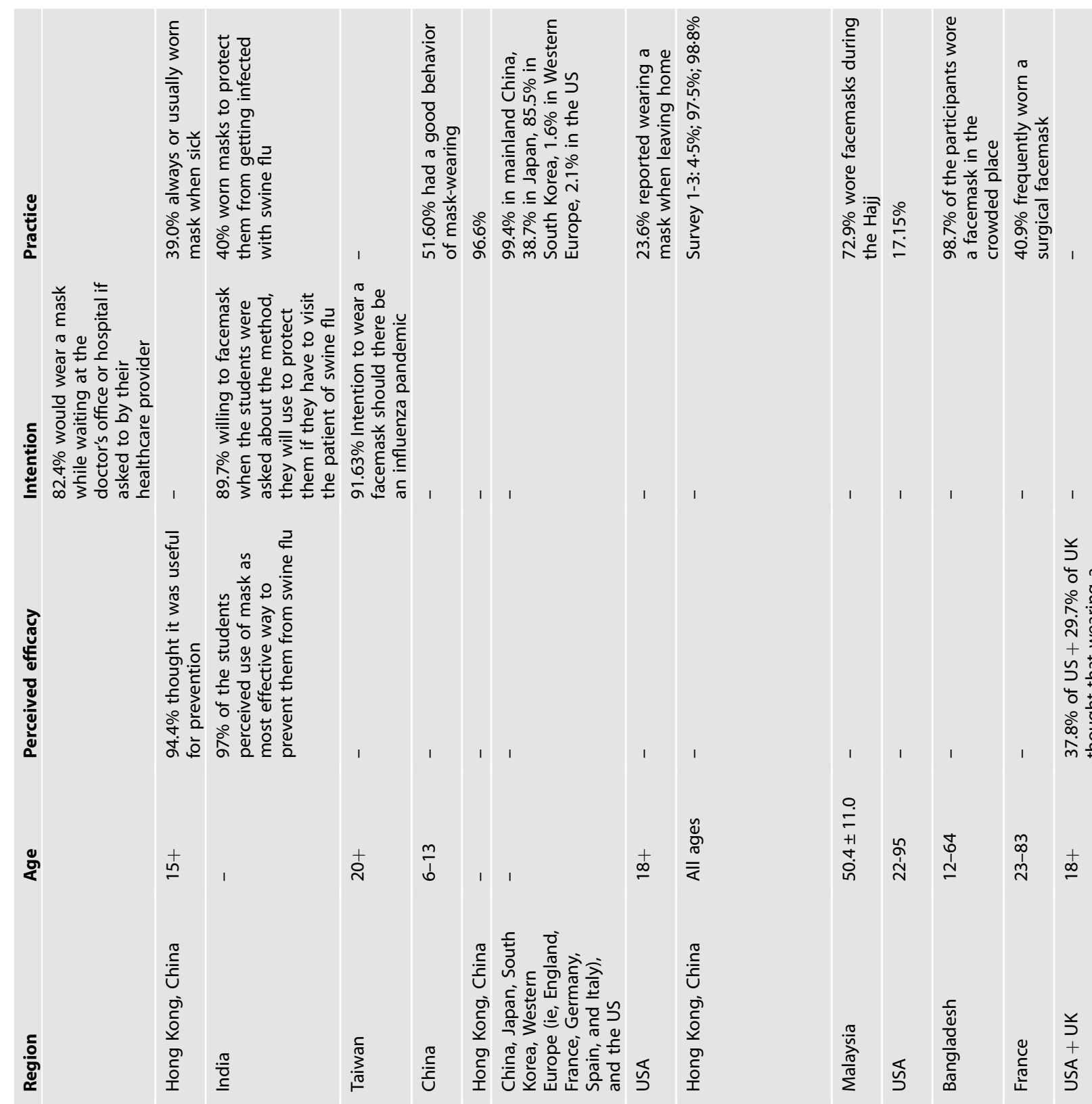

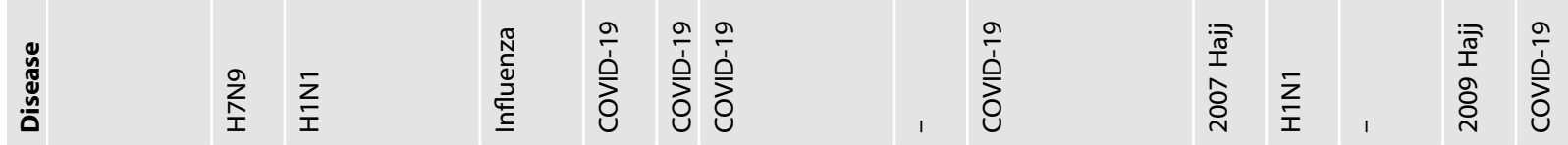

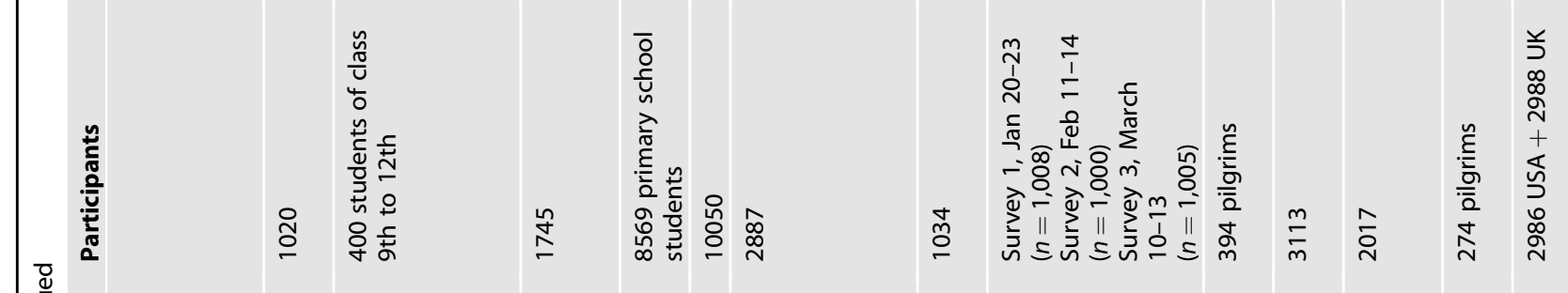

홍

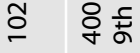

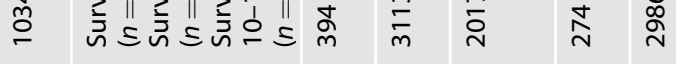

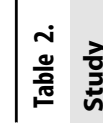

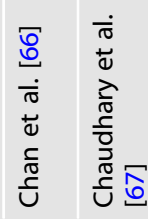

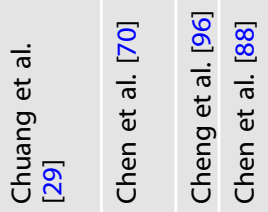

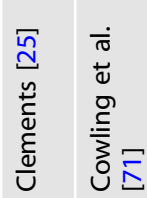

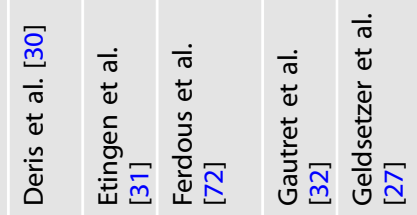




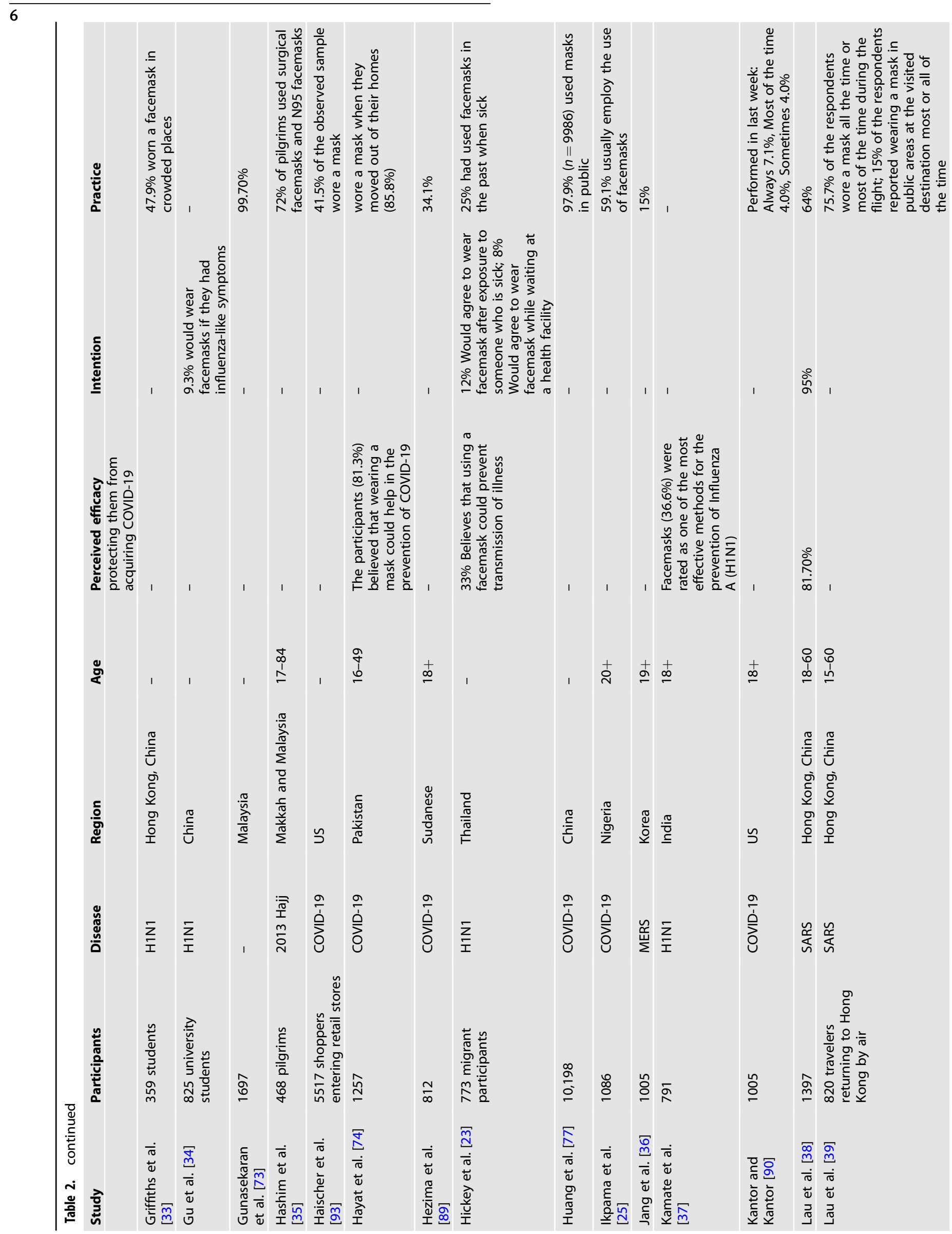



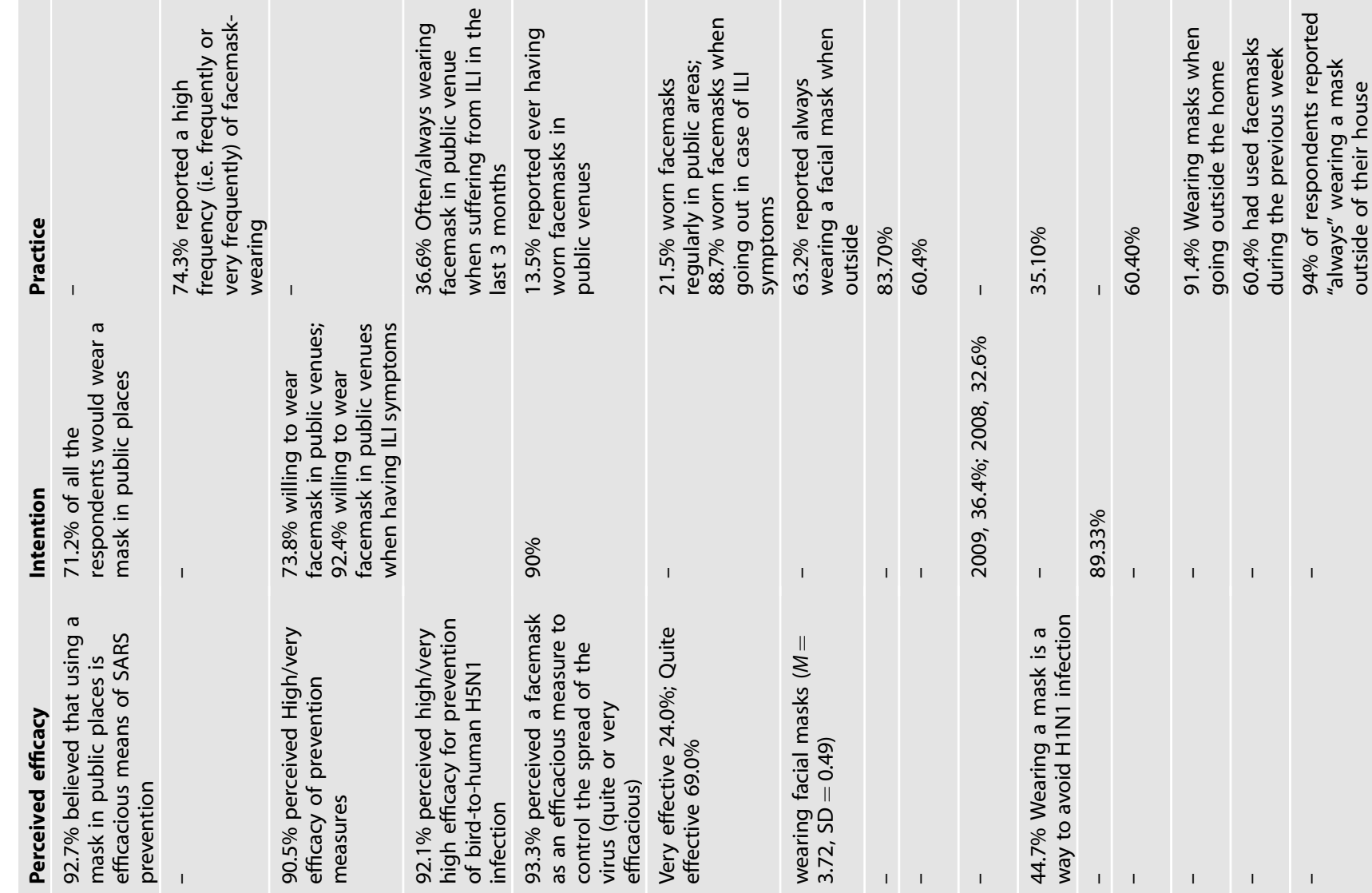

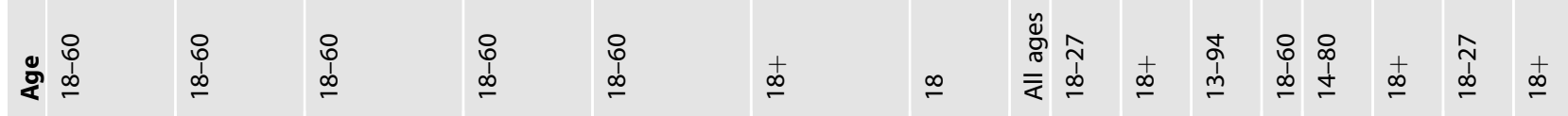

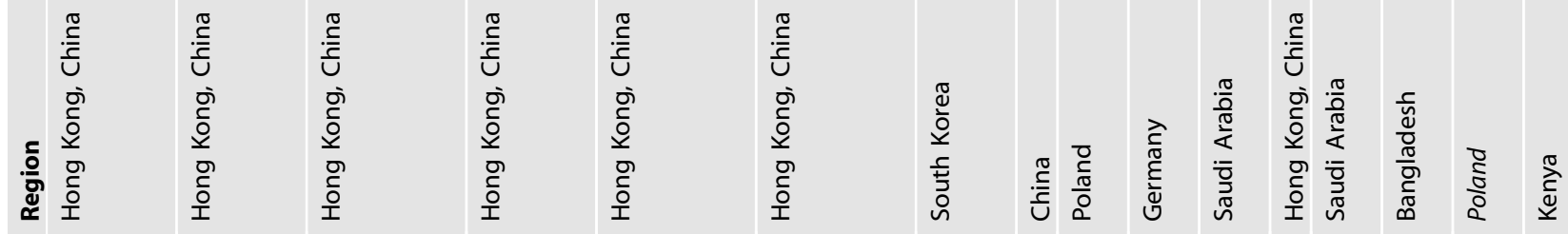

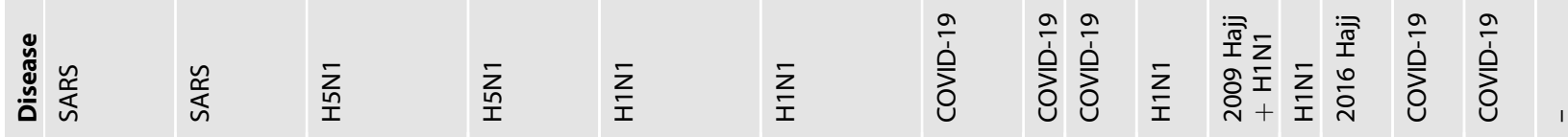

童

惫<smiles>CCCCCC1CCCCC1</smiles>

,

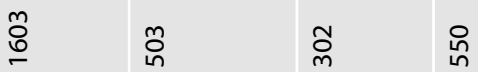

章

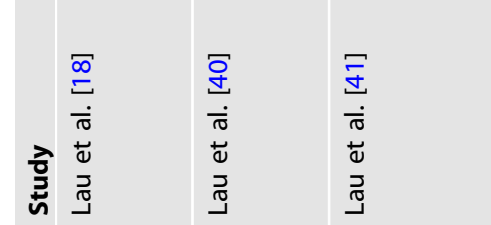

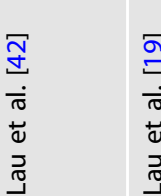

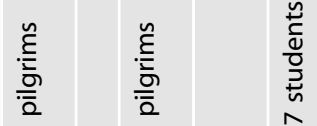

尕 

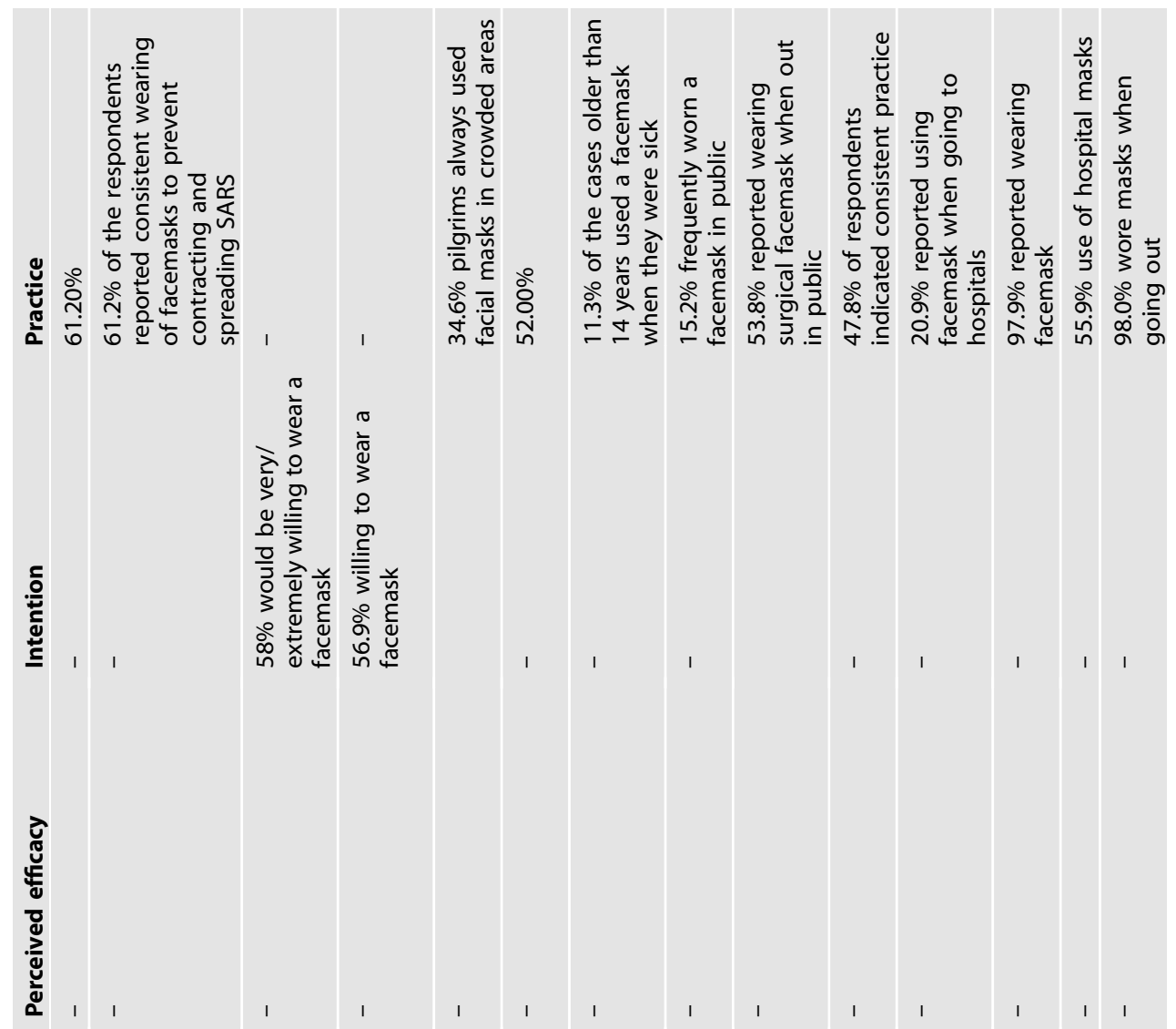

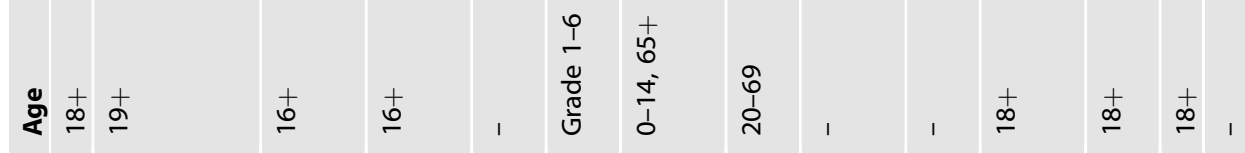

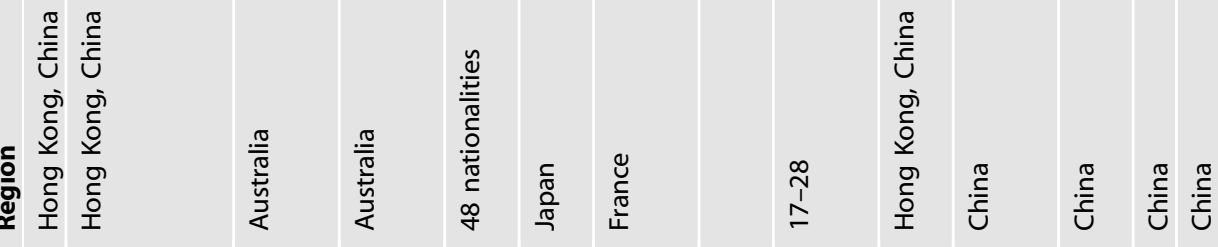

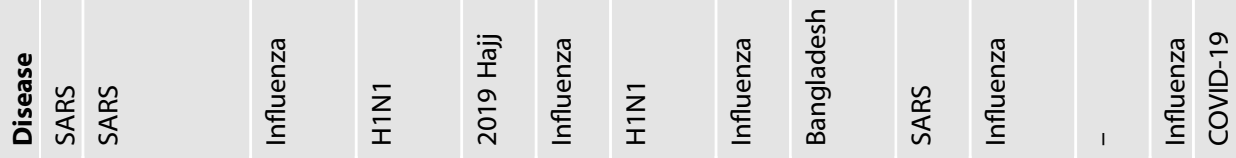

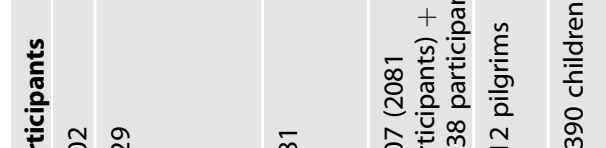

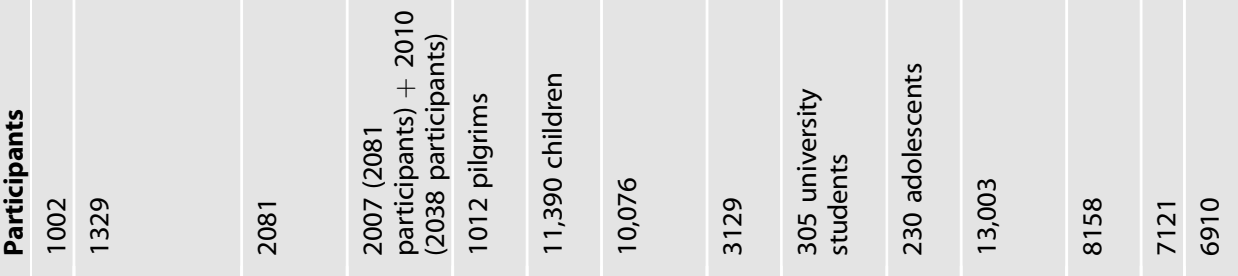

\begin{tabular}{|c|c|c|c|c|c|c|c|c|c|c|c|}
\hline 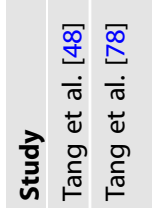 & 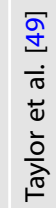 & 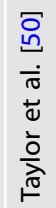 & 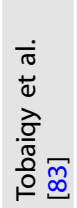 & 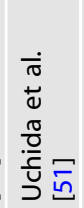 & 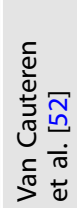 & $\begin{array}{l}\bar{m} \\
\underline{n} \\
\dot{\pi} \\
\tilde{\omega} \\
\frac{\pi}{0} \\
\frac{\sigma}{\pi} \\
\sum^{\pi}\end{array}$ & 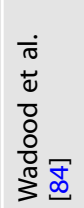 & 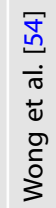 & 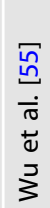 & 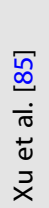 & 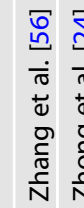 \\
\hline
\end{tabular}




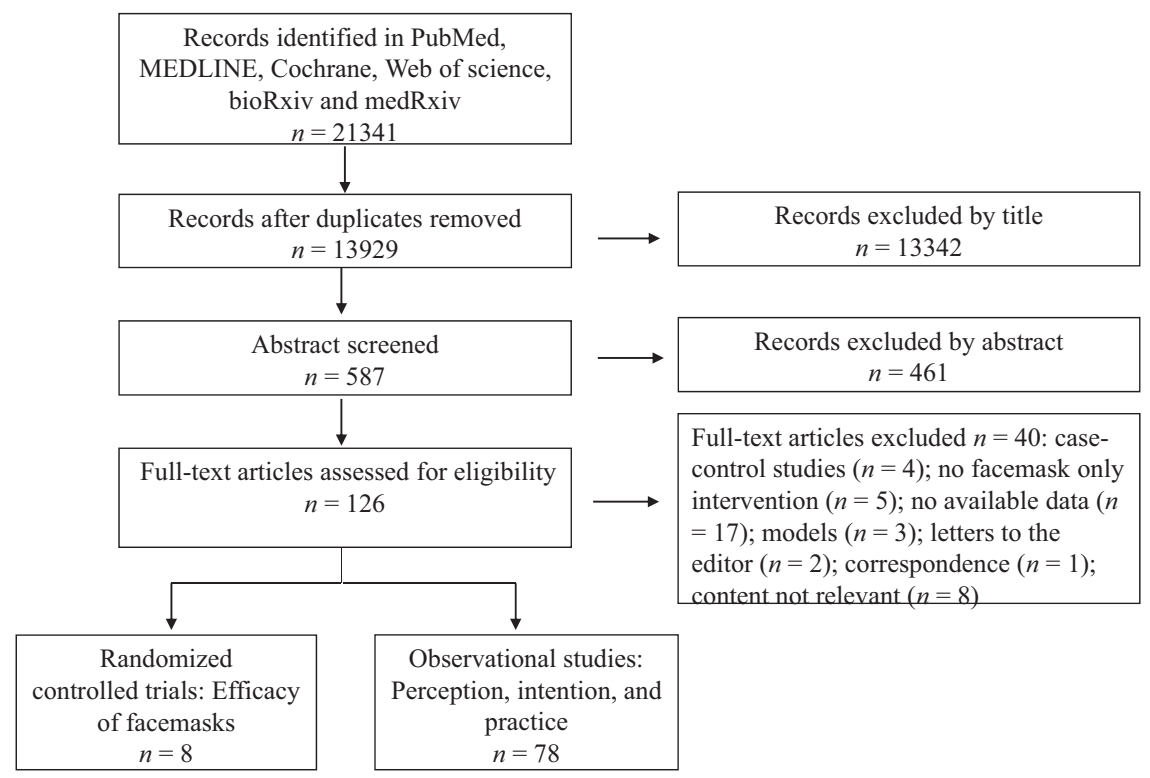

Fig. 1 Summary of the literature search and inclusion process.

\section{Efficacy of facemask use}

Characteristics of the eight RCT studies investigating the efficacy of facemasks are presented in Table 1. A total of 5,242 participants were included. Included RCT studies on estimating the efficacy of facemasks had been conducted in different settings. Five of these studies were conducted within households [6-10]. Two studies from the same group focused on the impact of facemasks on the incidence of ILI infection in university residence halls [11, 12]. A pilot RCT tested the efficacy of facemask use in the tents among Australian Hajj Pilgrim [13]. Among the studies conducted in households, three required both the index and the contacts or only contacts to wear facemasks, while two estimated the efficacy of facemasks as source control [7, 10]. Two studies were conducted with follow up more than two weeks [11, 12], while other six studies were followed up in a range of 5-14 days.

Meta-analysis of eight studies showed a significant protective effect (Fig. $2 . \leq 2$ weeks, $N=5242 ; \mathrm{OR}=0.84 ; 95 \% \mathrm{Cl}: 0.71-0.99 ; I^{2}=$ $0 \%)$. In the university residence halls, this protective effect was more pronounced if the intervention duration was more than two weeks (Fig. 2. > 2 weeks, $N=2261 ; \mathrm{OR}=0.76 ; 95 \% \mathrm{Cl}: 0.66-0.88 ; l^{2}=0 \%$ ). The subgroup analysis of intervention settings (households, resident halls or tents) and population (by index, contacts or both contacts and index) did not show any significant difference (Fig. S1, S2).

\section{Perception, intention, and practice towards facemask use}

Characteristics of the 78 studies [18, 19, 22-96] investigating the perception, intention, and practice of facemask are presented in Table 2. A total number of 151,228 participants were included, with 14 studies reported $(14,556)$ the rates of perception, 15 studies $(17,651)$ reported the rates of intention, and 63 studies $(151,228)$ reported the rates of practice.

In Fig. 3, the meta-analysis showed that $71 \%$ of respondents perceived facemasks to be effective for infection prevention, $68 \%$ of respondents would wear facemasks, and $54 \%$ of respondents wore facemasks for preventing respiratory infections. The subgroup analysis showed that most of the respondents from the West Pacific (90\%) perceived facemask use as a good way to prevent the transmission of respiratory infections, while a lower rate of respondents reported the same perception in Southeast Asia (56\%), Europe (47\%), Eastern Mediterranean (45\%), and Americas (38\%) (Fig. S3, S4). However, the subgroup analysis showed no significant difference in the rates of intention of wearing facemask in different regions (Fig. S5). There were also no significant differences of the perception and intention of facemask use among different diseases (Fig. S6, S7).

In terms of practice, there was a significant difference of practice rates among different diseases $(p=0.02)$. About $65 \%$ of the respondents reported wearing facemasks during the COVID-19 outbreak, $56 \%$ of the respondents reported wearing facemasks during the SARS outbreak, and less than 45\% reported wearing facemasks during the MERS, H1N1, H5N1, H7N9 and seasonal influenza outbreak (Fig. S8).

The subgroup analysis also showed significant differences in the rates of practice of wearing facemask in different regions $(p<$ $0.01)$. For all of the diseases, the participants reported higher rate of facemask-wearing in the West Pacific (63\%), followed by Southeast Asia (62\%), Africa (62\%), the Eastern Mediterranean (53\%), Americas (31\%) and Europe (28\%) (Fig. S9). During the COVID-19 pandemic, the participants reported the highest rate of facemask-wearing in the West Pacific (83\%), followed by Southeast Asia (82\%), Eastern Mediterranean (73\%) and Africa (62\%), Europe (33\%), and Americas (32\%) (Fig. S10). Global prevalence of perception, intention, and practice of facemask use among different countries or regions are shown in Fig. 4.

The subgroup analysis showed that most of the respondents perceived facemask use in public areas (93\%), when sick/having ILI symptoms $(94 \%)$ or during Pilgrimage $(75 \%)$ to be effective for preventing transmission (Fig. 3). A smaller proportion of respondents would wear facemasks in public areas (78\%), in hospital/ health facility (45\%), when sick/having ILI symptoms (62\%) or after exposure to infected patient (51\%) (Fig. S11 and S12). Moreover, $55 \%$ of respondents reported to wear facemasks in public areas, $64 \%$ reported to wear facemasks in crowded places, 38\% reported to wear facemasks in hospital/health facility, $48 \%$ reported to wear facemasks when sick/ having ILI symptoms and 52\% reported to wear facemasks during Pilgrimage (Fig. S13, S14). There were no significant differences of the perception, intention, and practice of facemask use among different places or situations (Fig. 3). The subgroup analysis of practice by sex and age did not show any significant difference.

Publication bias, quality assessment, and sensitivity analysis Significant publication bias was found for the perception ( $p=$ 0.001 ) towards facemask use. No publication bias was found 


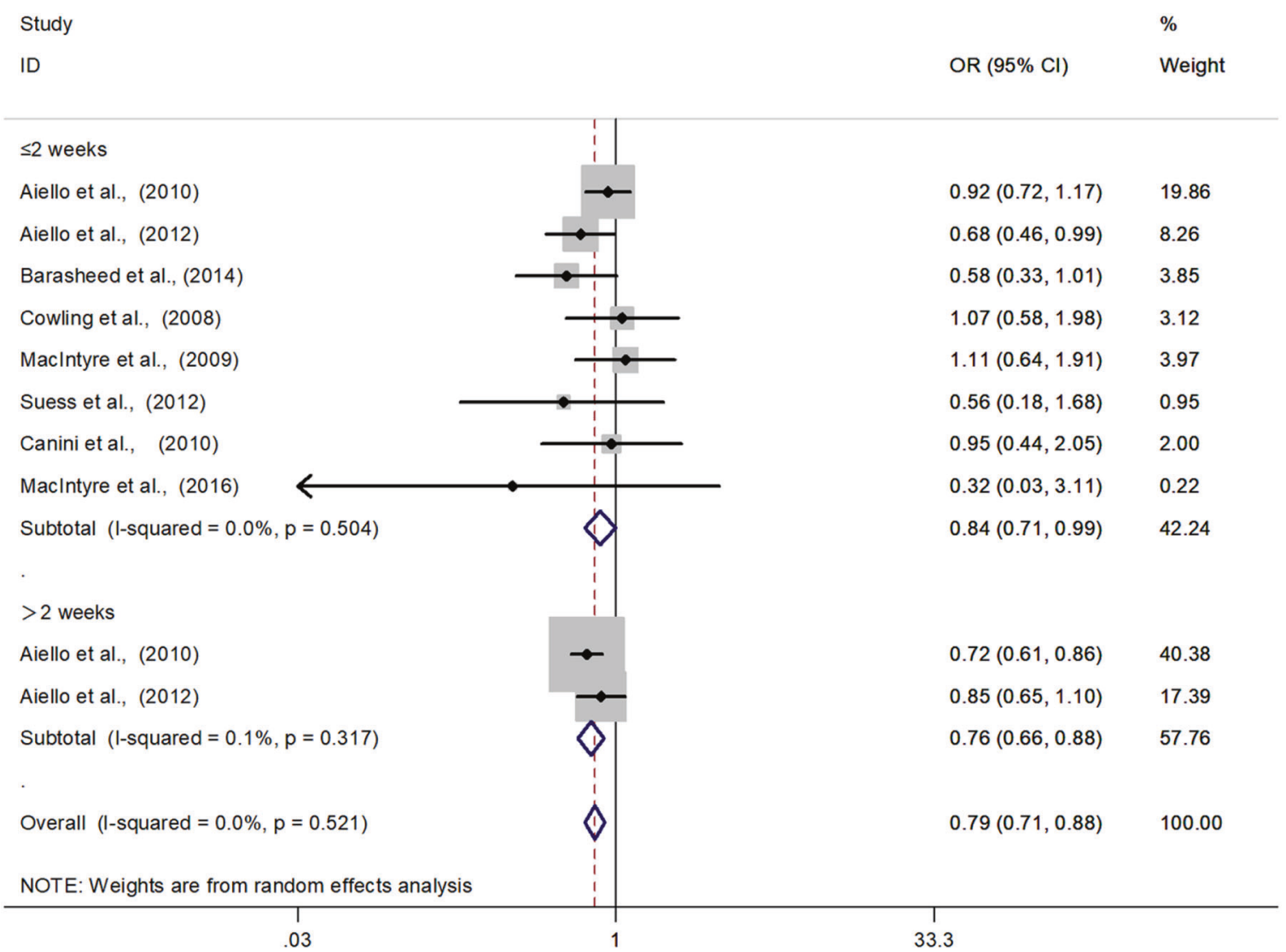

Fig. 2 Forest plots of meta-analysis to determine efficacy of facemasks in reducing respiratory infection among the general population. There is a significant protective effect if the duration of facemask use was more than two weeks. The results are expressed as odds ratios (ORs) and $95 \%$ confidence intervals $(95 \% \mathrm{CI})$.

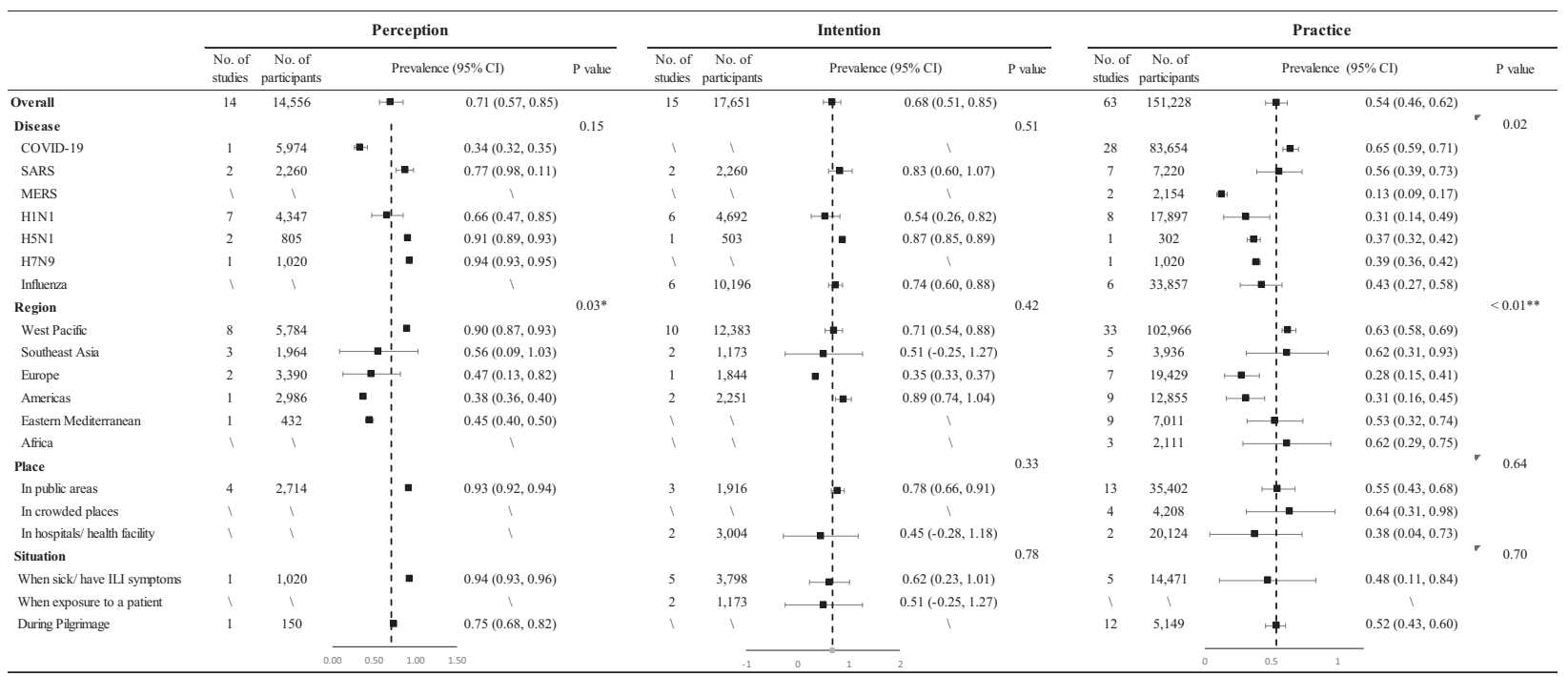

Fig. 3 Perception, intention, and practice towards facemask use in subgroups. We performed subgroup analyses of the perception, intention, and practice of facemask use, including different diseases, regions, places, and situations.

for the facemask efficacy, intention, and practice of facemasks use (Fig. S15, $p>0.05$ ). The quality assessment was reported in Table S3 for RCTs and Table S4 for studies on perception, intention, and practice of facemask use. The sensitivity analysis showed no significant impact on the RCT outcomes (Fig. S16).

\section{DISCUSSION}

In this systematic review and meta-analysis, we summarized the current evidence on the efficacy of facemask use for the prevention of respiratory infections among the general population. The meta-analysis shows that facemask use can reduce the risk of clinical symptoms of respiratory infection. Moreover, the 

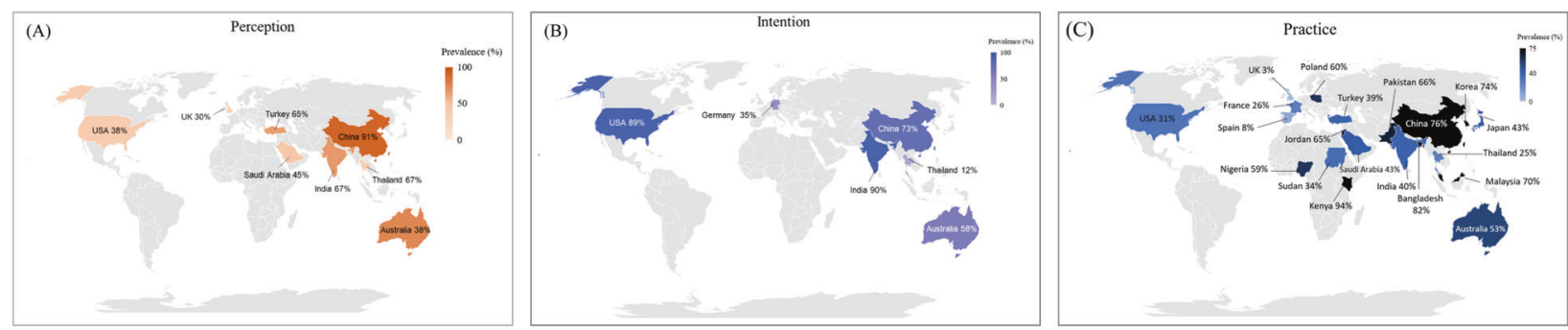

Fig. 4 Global prevalence of perception, intention, and practice of facemask use among the general population. A Perceived efficacy of facemask for preventing respiratory infection. B Intention of facemask use for preventing respiratory infection. C Practice of facemask use for preventing respiratory infection during the COVID-19.

results of this study showed that the protective effect was more pronounced when the duration of facemask use was longer than two weeks. We also found that $71 \%$ of respondents perceived facemask use to be effective for infection prevention, $68 \%$ of respondents would wear facemasks, and $54 \%$ of respondents wore facemasks for preventing respiratory infections. However, the perception and practice towards facemask use among general population varied in different regions and for different infectious diseases. Our results highlight the importance of facemask use among general populations and provide evidence for the governments and relevant organizations to make efforts to reduce the barriers in the use of facemasks to control the pandemic.

\section{Efficacy of facemask use}

Our results suggest facemask use may significantly reduce the clinical symptoms of respiratory infection. Facemasks are recommended for the prevention of infectious diseases transmitted through droplets and respirators for respiratory aerosols [97]. However, most of the RCTs included in this meta-analysis did not show a statistically significant effect of facemask use for preventing infection in community settings. This might be due to the relatively small sample size and low infection rate in community settings. After the pooled analysis with a much larger sample size, the prevention effect of facemask on infections could be more significant. According to a recent meta-analysis which pooled case-control, retrospective studies and RCTs (published in medRxiv preprint), a protective effect of facemasks was found among non-healthcare workers [15]. However, another previous meta-analysis of RCTs on facemask use reported no significant reduction in laboratory-confirmed influenza infections [14]. The authors of the meta-analysis suggest that the result may be related to limited sample size, only laboratory samples, and suboptimal adherence of facemask use in some studies [14].

A recent study demonstrated that disposable surgical masks could reduce the detection of influenza virus RNA in respiratory droplets and coronavirus RNA in aerosols, and had a higher tendency to reduce coronavirus RNA in respiratory droplets [98]. Evidence from a modeling study also supported the efficacy of facemask, which suggested that broad adoption of facemasks could meaningfully curtail community transmission of COVID-19 and reduce the peak of hospitalizations and deaths [99]. Recently a systematic review suggests that the efficacy of cloth facemask depends on its fabric material and polyester has the best filtration efficiency [100]. Similar with previous studies, our present study also strongly supports that facemask use (eg, surgical masks, longer than 2 weeks) can be an effective and accessible protection of infections of COVID-19 for general population. Further studies need to be conducted to explore the long-term efficacy of various facemasks on prevention of infections.

Our study also indicates the changing trends of overall perception, intention, and practice of facemask use. The results of our study showed that more than $70 \%$ of respondents perceived efficacy of facemask use and $68 \%$ of respondents would wear facemasks, but less than half of the respondents had put into practice. The rates of perception of efficacy and practice of facemask use were higher in West Pacific than that in other regions. The higher rates of practice of facemask use in West Pacific might be related to higher perception of efficacy of facemask use. [20] And lower rates of practice of facemask use in Europe and the Americas might be linked to lower perception of efficacy of facemask use. The results of this study also show a gap between intention and practice of facemask use in the Americas. In order to promote the prevention effect of facemasks in community settings, it is important to understand the factors related to compliance and barriers of facemask use (Fig. 5).

\section{Factors associated with compliance of facemask use}

Threat of disease. The subgroup analysis showed that different type of disease might affect the practice of facemask use. About $76 \%$ of the respondents wore facemasks during the COVID-19 outbreak, $56 \%$ of the respondents wore facemasks during the SARS outbreak, and less than $45 \%$ of the respondents wore facemasks during the MERS, H1N1, H5N1, H7N9 and seasonal influenza outbreaks. The results of this study indicate that infectivity and fatality of disease may be important factors influencing facemask use. Previous studies reported that perceived fatality of SARS and $\mathrm{H} 1 \mathrm{~N} 1$ was related to higher practice of facemask use in public areas [38] and crowded places [101], while the respondents who perceived less personal threat of SARS infection would not wear facemasks [54]. The respondents who thought that pandemic influenza was very likely to occur reported higher willingness to comply with wearing facemasks [65]. During the H1N1 outbreak, the most mentioned factors affecting respondents' decision to use facemask in public areas included the increasing number of local confirmed $\mathrm{H} 1 \mathrm{~N} 1$ cases and reported deaths of local H1N1 patients [19]. In all, perceived threat of disease could be one of the crucial reasons for the compliance of facemask use. During the COVID-19 pandemic, especially in the early stage, underestimating the infectivity and fatality of the pandemic may have reduced individuals' vigilance to prevent the COVID-19 pandemic (eg, many individuals in some countries, especially those who did not realize the severity of the COVID-19 pandemic). This is also very common among the young people, who got the information mainly from social media rather than the official government site for COVID-19. [102] The misleading information from the media and some leaders can also hinder the public to accept and use facemasks.

Geographic variation. Another influencing factor of facemask use might be different countries and regions. In this study, most of the respondents from the West Pacific perceived that wearing facemasks was beneficial to prevent the transmission of respiratory infections. The practice of facemask use also showed a tendency of higher rates in the West Pacific than in other regions. During the Manchurian plague epidemic in China in 1910, WU Liande, a Chinese doctor, transformed the cotton masks into protective equipment, which was the original "anti-plague mask" 


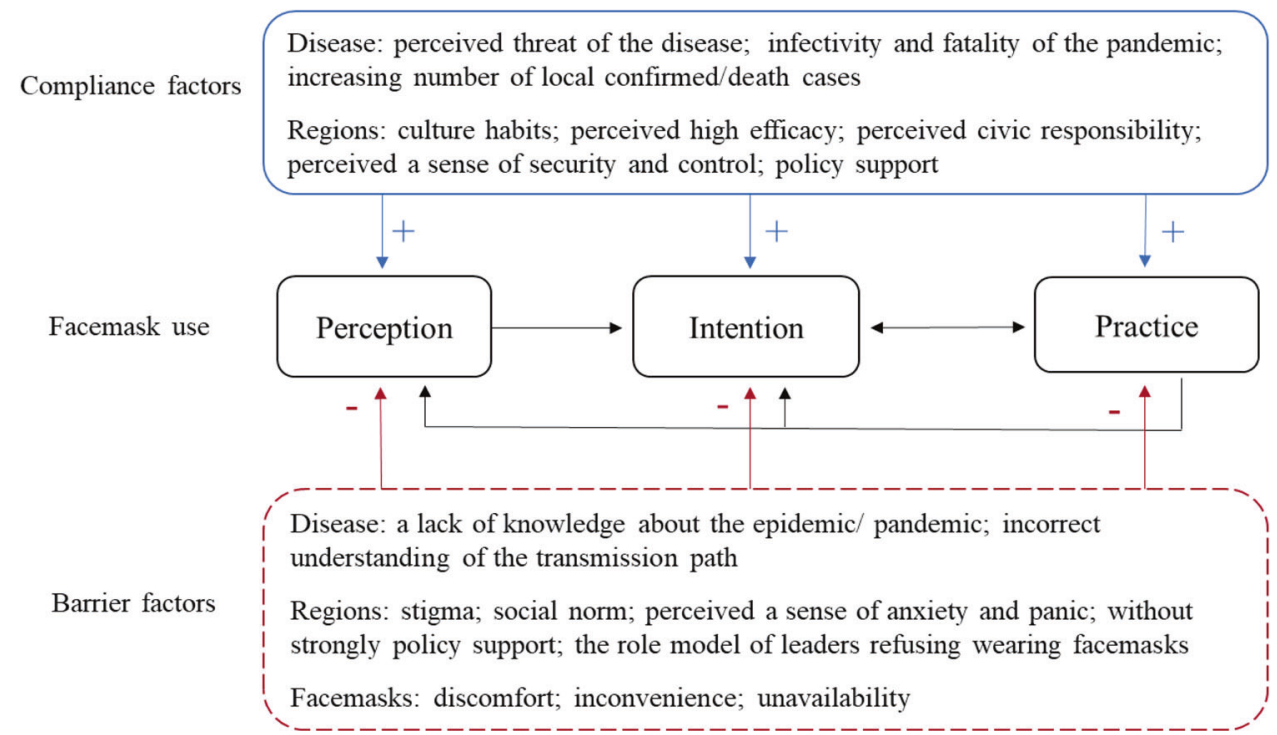

Fig. 5 The compliance related factors and barriers in the use of facemask. Factors associated with compliance of facemask use can be divided into threat of disease (e.g. perceived threat of disease) and geographic variation (e.g. perceived civic responsibility). Barrier factors of facemask use can be divided into knowledge of the diseases (e.g. a lack of knowledge of the disease), geographic variation (e.g. stigma), and feeling of facemask use (e.g. discomfort).

$[103,104]$. Over the next 100 years, this kind of facemask and its various modified versions were widely used in China. Especially during the SARS outbreak, facemask use was regarded as a remarkable social and health protective behavior and widely recognized by the Hong Kong population. [105] The use of facemask in public has been perceived as a new social norm, a form of civic responsibility, symbolic support for health care providers, and a tool for achieving a sense of control and security in China [105]. During the COVID-19 pandemic, high frequency of facemask use was significantly associated with lower anxiety and depression in China. [106] Regarded as the 'safety blanket', facemask use has been widespread in daily life in other Asian countries (eg, Japan), which is more likely to be driven by symbolic dimensions than by scientific evidence alone [107]. High rates of facemask use in East Asian countries may partly reflect the impact of Asian culture (eg, beliefs on facemask) and previous experience on facemask use during the pandemic.

The variation of different rates of facemask use underlines the collective and individual experience about benefits of facemask use, which leads to a high perception of efficacy of facemasks and high practice of facemask use. Besides, the policies supporting facemask use in these regions also have an important effect on the practice of facemask use during the COVID-19 pandemic. Due to the high acceptance of facemask use, the general population in these regions may own a strong motivation to follow these policies and guidelines of wearing facemasks in public areas to fight against COVID-19 pandemic. However, general population in some countries have different beliefs on the benefits of facemask use on curbing respiratory infections, different associations with covering the face and no long-standing habit of wearing facemasks. In the post-SARS era, facemasks have also been associated with stigma, as a sign of negative attributes and perceived to hinder recovery. [105] Besides, facemask-wearing was linked to plague and illness in some European countries, which could produce anxiety and panic in general population. This may partly explain the different individual coping behaviors and community practices among general population in different countries during the COVID-19 pandemic.

\section{Barriers in facemask use}

Stigma. The results of this meta-analysis showed that fewer than half of the European respondents perceived the benefits of facemask use in preventing infection and only about one-third of the respondents had worn facemasks during an epidemic/ pandemic. The reason of negative attitudes towards facemask use in these countries may partly result from the stigma associated with wearing facemask. In some contexts, masks are implicitly or explicitly opposed to the concepts of transparency and authenticity [108]. Facemask-wearing may thus regarded as a symbol of compliance, regulation, and manipulation, and the government's opposition to freedom of speech [108]. In an Australian survey, the most perceived barriers to wear a facemask was the presence of stigma [109]. Stigma and prejudice can hinder the intention of facemask use and can potentially cause the feeling of embarrassed or ashamed to wear facemasks $[38,110]$.

Discomfort and inconvenience. Discomfort and inconvenience are commonly reported factors that reduce the compliance of facemask use $[38,109]$. Wearing a facemask could cause breathing discomfort, even feeling of suffocation [61]. Other problems reported frequently were humidity, warmth, ear pain, poor fit in size and makeup coming off [110]. Moreover, wearing facemasks might also have a negative impact on interpersonal communication, limiting the making and reading of facial expressions. These negative feelings could impede the process from the intention to practice and reduce the facemasks use duration.

Unavailability. Due to the global shortage of medical and disposable surgical facemasks, the availability of facemasks had been quite a problem for general population. With widely spreading COVID-19, demand for personal protective equipment was much higher than average, leading to a worldwide shortage of medical masks for the general population. [111] Learning from the original experience of the Manchurian plague epidemic, the cloth facemasks might be a choice to substitute for medical masks. Despite the lack of high-quality evidence, a study suggested that homemade cloth facemasks showed only $15 \%$ less effective than surgical masks in preventing particulate emissions and five times more effective than not wearing facemasks [112]. And it can also be an expression to reduce the stigma of facemask use and build new social norms about facemask use.

There were a few potential limitations in this study. First of all, this study used self-reported clinical symptoms as the outcomes, which 
could be biased. However, previous RCTs did not test the laboratoryconfirmed outcomes for all the subjects, and therefore were unable to reflect the overall infection rate in intervention and control arms. Future RCTs ought to cover all subjects with laboratory-confirmed infection to provide more convincing evidence. Moreover, this study might not be able to include (1) recent ongoing research on facemasks, (2) high-quality research outcomes that might not be published in the studied databases but as technical reports or in gray literature, and (3) other important scientific findings which might not be publishing in English. Last, most of the included studies were observational studies and therefore more RCTs and long-term prospective studies should be needed to confirm the results in the future.

\section{CONCLUSION}

Overall, this systemic review suggests that facemask use may reduce the respiratory infection in general population in community settings. Given the efficacy of facemask use as a strategy of respiratory infection control, the policy makers should encourage facemask use among the general population for health protection. The present review also shows that there are differences in perception, intention, and practice of facemask use in different regions, and it likely reflects different impacts from various infectious diseases, regional culture and local policies. The governments and related organizations should make effort to increase the compliance of facemask use and reduce barriers associated with the use of facemasks, such as reducing stigma and prejudice on facemask use, public education through media and other communication channels.

\section{REFERENCES}

1. Bedford J, Farrar J, Ihekweazu C, Kang G, Koopmans M, Nkengasong J. A new twenty-first century science for effective epidemic response. Nature. 2019;575:130-6.

2. Jefferson T, Del Mar C, Dooley L, Ferroni E, Al-Ansary LA, Bawazeer GA, et al. Physical interventions to interrupt or reduce the spread of respiratory viruses: systematic review. BMJ. 2009;339:b3675.

3. Chu DK, AkI EA, Duda S, Solo K, Yaacoub S, Schünemann HJ. Physical distancing face masks, and eye protection to prevent person-to-person transmission of SARS-CoV-2 and COVID-19: a systematic review and meta-analysis. Lancet. 2020;395:1973-87.

4. World Health Organization. Advice on the use of masks in the community, during home care and in healthcare settings in the context of the novel coronavirus (COVID-19) outbreak. https://www.who.int/docs/default-source/documents/adviceon-the-use-of-masks-2019-ncov.pdf?sfvrsn=40619336 1\&download=trueps (Accessed Apr 1, 2021).

5. Centers for Disease Control and Prevention. How to Protect Yourself \& Others. https://www.cdc.gov/coronavirus/2019-nCoV/index.html (Accessed Apr 1, 2021).

6. Cowling BJ, Fung RO, Cheng CK, Fang VJ, Chan $\mathrm{KH}$, Seto WH, et al. Preliminary findings of a randomized trial of non-pharmaceutical interventions to prevent influenza transmission in households. PLoS ONE. 2008;3:e2101.

7. Canini L, Andreoletti L, Ferrari $P$, D'Angelo R, Blanchon $T$, Lemaitre $M$, et al. Surgical mask to prevent influenza transmission in households: a cluster randomized trial. PLOS ONE. 2010;5:e13998.

8. Suess T, Remschmidt C, Schink SB, Schweiger B, Nitsche A, Schroeder K, et al. The role of facemasks and hand hygiene in the prevention of influenza transmission in households: results from a cluster randomised trial; Berlin, Germany, 2009-2011. BMC Infect Dis. 2012;12:26.

9. Maclntyre CR, Cauchemez S, Dwyer DE, Seale H, Cheung P, Browne G, et al. Face mask use and control of respiratory virus transmission in households. Emerg Infect Dis. 2009;15:233-41.

10. Maclntyre $C R$, Zhang $Y$, Chughtai $A A$, Seale $H$, Zhang $D$, Chu $Y$, et al. Cluster randomised controlled trial to examine medical mask use as source control for people with respiratory illness. BMJ Open. 2016;6:e012330.

11. Aiello AE, Murray GF, Perez V, Coulborn RM, Davis BM, Uddin M, et al. Mask use, hand hygiene, and seasonal influenza-like illness among young adults: a randomized intervention trial. J Infect Dis. 2010;201:491-8.

12. Aiello AE, Perez V, Coulborn RM, Davis BM, Uddin M, Monto AS. Facemasks, hand hygiene, and influenza among young adults: a randomized intervention trial. PLOS ONE. 2012;7:e29744.
13. Barasheed O, Almasri N, Badahdah AM, Heron L, Taylor J, McPhee K, et al. Pilot randomised controlled trial to test effectiveness of facemasks in preventing influenza-like illness transmission among Australian Hajj pilgrims in 2011. Infect Disord Drug Targets. 2014;14:110-6.

14. Xiao J, Shiu EYC, Gao H, Wong JY, Fong MW, Ryu S, et al. Nonpharmaceutical measures for pandemic influenza in nonhealthcare settings-personal protective and environmental measures. Emerg Infect Dis. 2020;26:967-75.

15. Liang M, Gao L, Cheng C, Zhou Q, Uy JP, Heiner K, et al. Efficacy of face mask in preventing respiratory virus transmission: a systematic review and metaanalysis. Travel Med Infect Dis. 2020;36:101751.

16. Chaabna K, Doraiswamy S, Mamtani R, Cheema S. Facemask use in community settings to prevent respiratory infection transmission: a rapid review and metaanalysis. Int J Infect Dis. 2020;S1201-9712:32150-32150.

17. Chou R, Dana T, Jungbauer R, Weeks C \& McDonagh MS. Masks for prevention of respiratory virus infections, including SARS-CoV-2, in health care and community settings: a living rapid review. Ann Intern Med. 2020;173:542-55.

18. Lau JT, Yang X, Pang E, Tsui HY, Wong E, Wing YK. SARS-related perceptions in Hong Kong. Emerg Infect Dis. 2005;11:417-24.

19. Lau JT, Griffiths S, Choi KC, Tsui HY. Widespread public misconception in the early phase of the H1N1 influenza epidemic. J Infect. 2009;59:122-7.

20. Bish A, Michie S. Demographic and attitudinal determinants of protective behaviours during a pandemic: a review. Br J Health Psychol. 2010;15:797-824.

21. Sim SW, Moey KS, Tan NC. The use of facemasks to prevent respiratory infection: a literature review in the context of the Health Belief Model. Singap Med J. 2014;55:160-7.

22. Akan H, Gurol Y, Izbirak G, Ozdatli S, Yilmaz G, Vitrinel A, et al. Knowledge and attitudes of university students toward pandemic influenza: a cross-sectional study from Turkey. BMC Public Health. 2010;10:413.

23. Hickey J, Gagnon AJ, Jitthai N. Pandemic preparedness: perceptions of vulnerable migrants in Thailand towards WHO-recommended non-pharmaceutical interventions: a cross-sectional study. BMC Public Health. 2014;14:665.

24. Zhong BL, Luo W, Li HM, Zhang QQ, Liu XG, Li WT, et al. Knowledge, attitudes, and practices towards COVID-19 among Chinese residents during the rapid rise period of the COVID-19 outbreak: a quick online cross-sectional survey. Int J Biol Sci. 2020;16:1745-52.

25. Ikpama W, Mamerhi ET, Godswill OO. Knowledge, awareness and practicestowards COVID-19 in Nigeria during the ascent time of the COVID-19 episode. Gazi Med J. 2020;31:292-7.

26. Clements JM. Knowledge and behaviors toward COVID-19 among US residents during the early days of the pandemic: cross-sectional online questionnaire. JMIR Public Health Surveill. 2020;6:e19161-e19161.

27. Geldsetzer P. Use of rapid online surveys to assess people's perceptions during infectious disease outbreaks: a cross-sectional survey on COVID-19. J Med Internet Res. 2020;22:e18790.

28. Centers for Disease, C. \& Prevention. Experiences with influenza-like illness and attitudes regarding influenza prevention-United States, 2003-04 influenza season. MMWR Morb Mortal Wkly Rep. 2004;53:1156-8.

29. Chuang YC, Huang YL, Tseng KC, Yen CH, Yang LH. Social capital and healthprotective behavior intentions in an influenza pandemic. PLoS ONE. 2015;10: e0122970.

30. Deris ZZ, Hasan H, Sulaiman SA, Wahab MS, Naing NN, Othman NH. The prevalence of acute respiratory symptoms and role of protective measures among Malaysian hajj pilgrims. J Travel Med. 2010;17:82-88.

31. Etingen B, LaVela SL, Miskevics S, Goldstein B. Health information during the H1N1 influenza pandemic: did the amount received influence infection prevention behaviors? J Community Health. 2013;38:443-50.

32. Gautret $P$, Vu Hai V, Sani $S$, Doutchi $M$, Parola $P$, Brouqui $P$. Protective measures against acute respiratory symptoms in French pilgrims participating in the Hajj of 2009. J Travel Med. 2011;18:53-55.

33. Griffiths SM, Wong AH, Kim JH, Yung TK, Lau JT. Influence of country of study on student responsiveness to the H1N1 pandemic. Public Health. 2010;124:460-6.

34. Gu J, Zhong $Y$, Hao $Y$, Zhou D, Tsui $H$, Hao $C$, et al. Preventive behaviors and mental distress in response to $\mathrm{H} 1 \mathrm{~N} 1$ among university students in Guangzhou, China. Asia Pac J Public Health. 2015;27:Np1867-1879.

35. Hashim S, Ayub ZN, Mohamed Z, Hasan H, Harun A, Ismail N, et al. The prevalence and preventive measures of the respiratory illness among Malaysian pilgrims in 2013 Hajj season. J Travel Med. 2016;23:tav019.

36. Jang WM, Cho $S$, Jang $D H$, Kim UN, Jung $H$, Lee JY, et al. Preventive behavioral responses to the 2015 Middle East Respiratory Syndrome Coronavirus outbreak in Korea. Int J Environ Res Public Health. 2019;16:2161.

37. Kamate SK, Agrawal A, Chaudhary H, Singh K, Mishra P, Asawa K. Public knowledge, attitude and behavioural changes in an Indian population during the Influenza A (H1N1) outbreak. J Infect Dev Ctries. 2009;4:7-14.

38. Lau JT, Yang $X$, Tsui $H$, Pang E, Kim JH. SARS preventive and risk behaviours of Hong Kong air travellers. Epidemiol Infect. 2004;132:727-36. 
39. Lau JT, Yang X, Tsui HY, Pang E. SARS related preventive and risk behaviours practised by Hong Kong-mainland China cross border travellers during the outbreak of the SARS epidemic in Hong Kong. J Epidemiol Community Health. 2004;58:988-96.

40. Lau JT, Yang X, Tsui HY, Kim JH. Impacts of SARS on health-seeking behaviors in general population in Hong Kong. Prev Med. 2005;41:454-62.

41. Lau JT, Kim JH, Tsui HY, Griffiths S. Anticipated and current preventive behaviors in response to an anticipated human-to-human $\mathrm{H} 5 \mathrm{~N} 1$ epidemic in the Hong Kong Chinese general population. BMC Infect Dis. 2007;7:18.

42. Lau JT, Kim JH, Tsui HY, Griffiths S. Perceptions related to bird-to-human avian influenza, influenza vaccination, and use of face mask. Infection 2008;36:434-43.

43. Lau JT, Griffiths S, Choi KC, Lin C. Prevalence of preventive behaviors and associated factors during early phase of the H1N1 influenza epidemic. Am J Infect Control. 2010;38:374-80.

44. Meilicke G, Riedmann K, Biederbick W, Muller U, Wierer T, Bartels C. Hygiene perception changes during the influenza A H1N1 pandemic in Germany: incorporating the results of two cross-sectional telephone surveys 2008-2009. BMC Public Health. 2013;13:959.

45. Memish ZA, Assiri AM, Hussain R, Alomar I, Stephens G. Detection of respiratory viruses among pilgrims in Saudi Arabia during the time of a declared influenza A(H1N1) pandemic. J Travel Med. 2012;19:15-21.

46. Mo PK, Lau JT. Illness representation on H1N1 influenza and preventive behaviors in the Hong Kong general population. J Health Psychol. 2015;20:1523-33.

47. Mohammed M, Albouq N, Bakhashwain N, Nasser Y, Jarrah A. Knowledge and attitude regarding preventive measures among pilgrims during Hajj, Madinah, Kingdom of Saudi Arabia, 2016. Indo Am J Pharm Sci. 2019;6:2877-84.

48. Tang CS, Wong CY. An outbreak of the severe acute respiratory syndrome: predictors of health behaviors and effect of community prevention measures in Hong Kong, China. Am J Public Health. 2003;93:1887-8.

49. Taylor M, Raphael B, Barr M, Agho K, Stevens G, Jorm L. Public health measures during an anticipated influenza pandemic: factors influencing willingness to comply. Risk Manag Health Policy. 2009;2:9-20.

50. Taylor MR, Stevens GJ, Agho KE, Kable SA, Raphael B. Crying wolf? Impact of the H1N1 2009 influenza pandemic on anticipated public response to a future pandemic. Med J Aust. 2012;197:561-4.

51. Uchida $M$, Kaneko $M$, Hidaka $Y$, Yamamoto $H$, Honda $T$, Takeuchi $S$, et al. Effectiveness of vaccination and wearing masks on seasonal influenza in Matsumoto City, Japan, in the 2014/2015 season: an observational study among all elementary schoolchildren. Prev Med Rep. 2017;5:86-91.

52. Van Cauteren D, Vaux S, de Valk H, Le Strat Y, Vaillant V, Levy-Bruhl D. Burden of influenza, healthcare seeking behaviour and hygiene measures during the $A$ (H1N1)2009 pandemic in France: a population based study. BMC Public Health. 2012;12:947.

53. Wada K, Oka-Ezoe K, Smith DR. Wearing face masks in public during the influenza season may reflect other positive hygiene practices in Japan. BMC Public Health. 2012;12:1065.

54. Wong CY, Tang CS. Practice of habitual and volitional health behaviors to prevent severe acute respiratory syndrome among Chinese adolescents in Hong Kong. J Adolesc Health. 2005;36:193-200.

55. Wu S, Ma C, Yang Z, Yang P, Chu Y, Zhang H, et al. Hygiene behaviors associated with influenza-like illness among adults in Beijing, China: a large, populationbased survey. PLoS ONE. 2016;11:e0148448.

56. Zhang Y, Wu SS, Yang P, Li C, Chu YH, Hua WY, et al. Association between socio-economic status indicators and adoption of preventive measures for influenza among Beijing residents: a cross-sectional study. Public Health. 2016;140:282-5.

57. Ahmad I, Altaf S, Ahmad HM. Assessment of knowledge, practice and barrier in use of facemask among university students. Pak J Med Sci. 2017;11:1657-8.

58. Allison MA, Guest-Warnick G, Nelson D, Pavia AT, Srivastava R, Gesteland PH, et al. Feasibility of elementary school children's use of hand gel and facemasks during influenza season. Influenza Other Respir Viruses. 2010;4:223-9.

59. Al-Mohrej OA, Al-Shirian SD, Al-Otaibi SK, Tamim HM, Masuadi EM, Fakhoury HM. Is the Saudi public aware of Middle East respiratory syndrome? J Infect Public Health. 2016;9:259-66.

60. Alqahtani AS, BinDhim NF, Tashani M, Willaby HW, Wiley KE, Heywood AE, et al. Pilot use of a novel smartphone application to track traveller health behaviour and collect infectious disease data during a mass gathering: Hajj pilgrimage 2014. J Epidemiol Glob Health. 2016;6:147-55.

61. Alqahtani AS, Wiley KE, Tashani M, Willaby HW, Heywood AE, BinDhim NF, et al. Exploring barriers to and facilitators of preventive measures against infectious diseases among Australian Hajj pilgrims: cross-sectional studies before and after Hajj. Int J Infect Dis. 2016;47:53-59.

62. Alqahtani AS, Althimiri NA, BinDhim NF. Saudi Hajj pilgrims' preparation and uptake of health preventive measures during Hajj 2017. J Infect Public Health. 2019;12:772-6.
63. Azman MA, Yusof SAM, Abdullah I, Mohamad I, Mohammed JS. Factors influencing face mask selection and design specifications: results from pilot study amongst Malaysian Umrah pilgrims. J Teknol. 2017;79:7-15.

64. Balaban V, Stauffer WM, Hammad A, Afgarshe M, Abd-Alla M, Ahmed Q, et al. Protective practices and respiratory illness among US travelers to the 2009 Hajj. J Travel Med. 2012;19:163-8.

65. Barr M, Raphael B, Taylor M, Stevens G, Jorm L, Giffin M, et al. Pandemic influenza in Australia: using telephone surveys to measure perceptions of threat and willingness to comply. BMC Infect Dis. 2008;8:117.

66. Chan EY, Cheng CK, Tam G, Huang Z, Lee P. Knowledge, attitudes, and practices of Hong Kong population towards human A/H7N9 influenza pandemic preparedness, China, 2014. BMC Public Health. 2015;15:943.

67. Chaudhary V, Singh RK, Agrawal VK, Agarwal A, Kumar R, Sharma M. Awareness, perception and myths towards swine flu in school children of Bareilly, Uttar Pradesh. Indian J Public Health. 2010;54:161-4.

68. Alzoubi $\mathrm{H}$, Alnawaiseh N, Al-Mnayyis AA, Abu-Lubad M, Aqel A, Al-Shagahin $\mathrm{H}$. COVID-19-knowledge, attitude and practice among medical and non-medical university students in Jordan. J Pure Appl Microbiol. 2020;14:17-24.

69. Azlan AA, Hamzah MR, Sern TJ, Ayub SH \& Mohamad E. Public knowledge, attitudes and practices towards COVID-19: a cross-sectional study in Malaysia. PLoS ONE. 2020;15:e0233668.

70. Chen X, Ran L, Liu Q, Hu Q, Du X \& Tan X. Hand hygiene, mask-wearing behaviors and its associated factors during the COVID-19 epidemic: a crosssectional study among primary school students in Wuhan, China. Int J Environ Res Public Health. 2020;17:2893.

71. Cowling BJ, Ali ST, Ng TWY, Tsang TK, Li JCM, Fong MW, et al. Impact assessment of non-pharmaceutical interventions against coronavirus disease 2019 and influenza in Hong Kong: an observational study. Lancet Public Health. 2020;5: E279-E288.

72. Ferdous MZ, Saiful Islam M, Sikder MT, Mosaddek ASM, Zegarra-Valdivia JA \& Gozal, D. Knowledge, attitude, and practice regarding COVID-19 outbreak in Bangladeshi people: an online-based cross-sectional study. MedRxiv. 2020. https://doi.org/10.1101/2020.05.26.20105700.

73. Gunasekaran GH, Gunasekaran SSS, Gunasekaran SS, Zaimi, NSI \& Abdul Halim NA. Prevalence of facemask use among general public when visiting wet market during Covid-19 pandemic: an observational study. MedRxiv. 2020. https://doi. org/10.1101/2020.05.17.20105023.

74. Hayat K, Rosenthal M, Xu S, Arshed M, Li P, Zhai P, et al. View of Pakistani residents toward coronavirus disease (COVID-19) during a rapid outbreak: a rapid online survey. Int J Environ Res Public Health. 2020;17:3347.

75. Aguero F, Adell MN, Perez Gimenez A, Lopez Medina MJ, Garcia Continente X. Adoption of preventive measures during and after the 2009 influenza A (H1N1) virus pandemic peak in Spain. Prev Med. 2011;53:203-6.

76. Al-Jasser FS, Kabbash IA, Almazroa MA, Memish ZA. Patterns of diseases and preventive measures among domestic hajjis from Central, Saudi Arabia. Saudi Med J. 2012;33:879-86.

77. Huang $Y$, Wu $Q$, Wang $P, X u Y$, Wang $L$, Zhao $Y$, et al. Measures undertaken in China to avoid COVID-19 infection: internet-based, cross-sectional survey study. J Med Internet Res. 2020;22:e18718.

78. Tang CS, Wong CY. Factors influencing the wearing of facemasks to prevent the severe acute respiratory syndrome among adult Chinese in Hong Kong. Prev Med. 2004;39:1187-93.

79. Lee M \& You M. Psychological and behavioral responses in South Korea during the early stages of coronavirus disease 2019 (COVID-19). Int J Environ Res Public Health. 2020;17:2977.

80. Liu X, Luo WT, Li Y, Li CN, Hong ZS, Chen HL, et al. Psychological status and behavior changes of the public during the COVID-19 epidemic in China. Infect Dis Poverty. 2020;9:58.

81. Quaife M, van Zandvoort K, Gimma A, Shah K, McCreesh N, Prem K, et al. The impact of COVID-19 control measures on social contacts and transmission in Kenyan informal settlements. MedRxiv. 2020. https://doi.org/10.1101/ 2020.06.06.20122689.

82. Szepietowski JC, Matusiak $Ł$, Szepietowska M, Krajewski PK, Białynicki-Birula R. Face mask-induced itch: a self-questionnaire study of 2,315 responders during the COVID-19 pandemic. Acta Derm Venereol 2020;100:adv00152.

83. Tobaiqy M, Almudarra SS, Shams MM, Amer SA, Alcattan MF \& Alhasan AH. Assessment of experiences of preventive measures practice including vaccination history and health education among Umrah Pilgrims in Saudi Arabia, 1440H-2019. MedRxiv. https://doi.org/10.1101/2020.06.09.20126581.

84. Wadood MA, Mamun A, Rafi MA, Islam MK, Mohd S, Lee Lee L, et al. Knowledge, attitude, practice and perception regarding COVID-19 among students in Bangladesh: Survey in Rajshahi University. MedRxiv. 2020. https://doi.org/10.1101/ 2020.04.21.20074757

85. Xu H, Gan Y, Zheng D, Wu B, Zhu X, Xu C, et al. The relationship between COVID19 infection and risk perception, knowledge, attitude as well as four non- 
pharmaceutical interventions (NPIs) during the late period of the COVID-19 Epidemic In China-An Online Cross-sectional Survey of 8158 Adults. MedRxiv. 2020. https://doi.org/10.1101/2020.06.02.20120808.

86. Abdulah DM, Aziz Qazli SS \& Suleman SK. Response of the public to preventive measures of coronavirus infection in Iraqi Kurdistan. Disaster Med Public Health Prep. 2020;1-22. https://doi.org/10.1017/dmp.2020.233.

87. Ayhan Başer D, Çevik M, Gümüştakim Ş \& Başara E. Assessment of individuals' attitude, knowledge and anxiety toward Covid 19 at the first period of the outbreak in Turkey: a web based cross-sectional survey. Int J Clin Pract. 2020; e13622. https://doi.org/10.1111/ijcp.13622.

88. Chen YJ, Qin G, Chen J, Xu JL, Feng DY, Wu XY, et al. Comparison of facetouching behaviors before and during the Coronavirus Disease 2019 pandemic. JAMA Netw Open. 2020;3:e2016924.

89. Hezima A, Aljafari A, Aljafari A, Mohammad A, Adel I. Knowledge, attitudes, and practices of Sudanese residents towards COVID-19. East Mediterr Health J. 2020;26:646-51.

90. Kantor BN, Kantor J. Non-pharmaceutical interventions for pandemic COVID-19: a cross-sectional investigation of US General Public Beliefs, Attitudes, and Actions. Front Med. 2020;7:384-384.

91. Matusiak $\measuredangle$, Szepietowska M, Krajewski PK, Białynicki-Birula R \& Szepietowsk, JC. The use of face masks during the COVID-19 pandemic in Poland: a survey study of 2315 young adults. Dermatol Ther. 2020. https://doi.org/10.1111/dth.13909, e13909.

92. Rahman A \& Sathi NJ. Knowledge, attitude, and preventive practices toward COVID-19 among Bangladeshi internet users. Electron J Gen Med. 2020;17: em245.

93. Haischer MH, Beilfuss R, Hart MR, Opielinski L, Wrucke D, Zirgaitis G, et al. Who is wearing a mask? Gender-, age-, and location-related differences during the COVID19 pandemic. MedRxiv. 2020. https://doi.org/10.1101/2020.07.13.20152736.

94. Beckage B, Buckley TE \& Beckage ME. Prevalence of mask wearing in northern Vermont in response to SARS-CoV-2. MedRxiv. 2020. https://doi.org/10.1101/ 2020.07.23.20158980.

95. Bowman L, Kwok KO, Redd R, Yi Y, Ward H, Wei WI, et al. Public perceptions and preventive behaviours during the early phase of the COVID-19 pandemic: a comparative study between Hong Kong and the United Kingdom. MedRxiv. https://doi.org/10.1101/2020.08.06.20169409.

96. Cheng VC, Wong SC, Chuang VW, So SY, Chen JH, Sridhar S, et al. The role of community-wide wearing of face mask for control of coronavirus disease 2019 (COVID-19) epidemic due to SARS-CoV-2. J Infect. 2020;81:107-14.

97. Maclntyre $C R$, Chughtai $A A$. Facemasks for the prevention of infection in healthcare and community settings. BMJ. 2015;350:h694.

98. Leung CC, Lam TH, Cheng KK. Mass masking in the COVID-19 epidemic: people need guidance. Lancet. 2020;395:945.

99. Eikenberry SE, Mancuso M, lboi E, Phan T, Eikenberry K, Kuang Y, et al. To mask or not to mask: Modeling the potential for face mask use by the general public to curtail the COVID-19 pandemic. Infect Dis Model. 2020;5:293-308.

100. Rizki SA, Kurniawan A. Efficacy of cloth mask in reducing COVID-19 transmission: a literature review. Kesmas: Natl Public Health J. 2020;15:43-48.

101. Hasan F, Khan MO, Ali M. Swine flu: knowledge, attitude, and practices survey of medical and dental students of Karachi. Cureus. 2018;10:e2048.

102. Adella Halim D, Kurniawan A, Agung FH, Angelina S, Jodhinata C, Winata S, et al. Understanding of young people about COVID-19 during early outbreak in Indonesia. Asia Pac J Public Health. 2020;32:363-5.

103. Lynteris C. Plague masks: the visual emergence of anti-epidemic personal protection equipment. Med Anthropol. 2018;37:442-57.

104. Spooner JL. History of surgical face masks. AORN J. 1967;5:76-80.

105. Siu JY. Qualitative study on the shifting sociocultural meanings of the facemask in Hong Kong since the severe acute respiratory syndrome (SARS) outbreak: implications for infection control in the post-SARS era. Int J Equity Health. 2016;15:73.

106. Wang C, Pan R, Wan X, Tan Y, Xu L, Ho CS, et al. Immediate psychological responses and associated factors during the initial stage of the 2019 Coronavirus Disease (COVID-19) epidemic among the general population in China. Int J Environ Res Public Health. 2020;17:1729.

107. Burgess A, Horii M. Risk, ritual and health responsibilisation: Japan's 'safety blanket' of surgical face mask-wearing. Socio Health Illn. 2012;34:1184-98.

108. Sin MSY. Masking fears: SARS and the politics of public health in China. Crit Public Health. 2016;26:88-98.
109. Maguire PA, Reay RE, Looi JC. Nothing to sneeze at-uptake of protective measures against an influenza pandemic by people with schizophrenia: willingness and perceived barriers. Australas Psychiatry. 2019;27:171-8.

110. Morishima $\mathrm{M}$, Kishida $\mathrm{K}$. Understanding attitudes toward hygiene mask use in Japanese daily life by using a repeated cross-sectional survey. Work 2018;61:303-11.

111. Stone TE, Kunaviktikul W, Omura M \& Petrini, M. Editorial: facemasks and the Covid 19 pandemic: What advice should health professionals be giving the general public about the wearing of facemasks? Nurs Health Sci. 2020. https:// doi.org/10.1111/nhs.12724.

112. Davies A, Thompson KA, Giri K, Kafatos G, Walker J, Bennett A. Testing the efficacy of homemade masks: would they protect in an influenza pandemic? Disaster Med Public Health Prep. 2013;7:413-8.

\section{ACKNOWLEDGEMENTS}

National Natural Science Foundation of China (no. 81761128036, 82171514, 81821092, 82001404, and 81901345), Special Research Fund of PKUHSC for Prevention and Control of COVID-19 and the Fundamental Research Funds for the Central Universities (no. BMU2020HKYZX008), National Key Research and Development Program of China (no. 2021YFC0863700, 2019YFA0706200) and China Medical Board Grant \#21-432.

\section{AUTHOR CONTRIBUTIONS}

L.L., J.S., A.Y.P.B., and H.L. designed the study. H.L., K.Y., and Y.K.S. conducted data extraction, analysis, drafted the manuscript, and interpreted the results. H.L. and S.Z.S developed the search strategy and conducted data retrieval. Y.B.Z., S.Z.S., and Y.X.Z. screened the abstracts and conducted full-text screening. H.L. and Y.Y.X. verified the data. L.L., Y.P.B., and J.S. supervised the meta-analysis, contributed to interpreting the results, and revised the manuscript. Y.Z., Y.J.W., S.S.T., Y.M.G., T.T.F., X.L., N.G., S.Y.S.W. E.Y.Y.C., W.Y., S.W.S., and M.S.R. contributed to discussions.

\section{COMPETING INTERESTS}

The authors declare no competing interests.

\section{ADDITIONAL INFORMATION}

Supplementary information The online version contains supplementary material available at https://doi.org/10.1038/s41398-022-01814-3.

Correspondence and requests for materials should be addressed to Yan-Ping Bao, Jie Shi or Lin Lu.

Reprints and permission information is available at http://www.nature.com/ reprints

Publisher's note Springer Nature remains neutral with regard to jurisdictional claims in published maps and institutional affiliations.

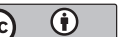

Open Access This article is licensed under a Creative Commons Attribution 4.0 International License, which permits use, sharing, adaptation, distribution and reproduction in any medium or format, as long as you give appropriate credit to the original author(s) and the source, provide a link to the Creative Commons license, and indicate if changes were made. The images or other third party material in this article are included in the article's Creative Commons license, unless indicated otherwise in a credit line to the material. If material is not included in the article's Creative Commons license and your intended use is not permitted by statutory regulation or exceeds the permitted use, you will need to obtain permission directly from the copyright holder. To view a copy of this license, visit http://creativecommons. org/licenses/by/4.0/.

(c) The Author(s) 2022 